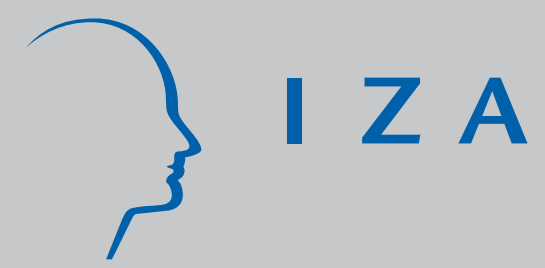

IZA DP No. 8288

Search and Retirement under Asymmetric Information

Sheng Bi

François Langot

June 2014

Forschungsinstitut zur Zukunft der Arbeit Institute for the Study of Labor 


\title{
Search and Retirement under Asymmetric Information
}

\author{
Sheng Bi \\ Paris School of Economics (PSE) \\ and Université de Paris 1 (CES) \\ François Langot \\ Université du Mans (GAINS-TEPP-IRA), \\ PSE, Banque de France and IZA
}

Discussion Paper No. 8288

June 2014

IZA

P.O. Box 7240

53072 Bonn

Germany

Phone: +49-228-3894-0

Fax: +49-228-3894-180

E-mail: iza@iza.org

\begin{abstract}
Any opinions expressed here are those of the author(s) and not those of IZA. Research published in this series may include views on policy, but the institute itself takes no institutional policy positions. The IZA research network is committed to the IZA Guiding Principles of Research Integrity.

The Institute for the Study of Labor (IZA) in Bonn is a local and virtual international research center and a place of communication between science, politics and business. IZA is an independent nonprofit organization supported by Deutsche Post Foundation. The center is associated with the University of Bonn and offers a stimulating research environment through its international network, workshops and conferences, data service, project support, research visits and doctoral program. IZA engages in (i) original and internationally competitive research in all fields of labor economics, (ii) development of policy concepts, and (iii) dissemination of research results and concepts to the interested public.
\end{abstract}

IZA Discussion Papers often represent preliminary work and are circulated to encourage discussion. Citation of such a paper should account for its provisional character. A revised version may be available directly from the author. 


\section{ABSTRACT}

\section{Search and Retirement under Asymmetric Information ${ }^{*}$}

We consider a labor market where the competitive search equilibrium is inefficient due to asymmetrical information. At the time when firms commit to specific hiring costs, workers hold private information on their intention of entering into retirement before the termination of the contract. When retirement is an event which occurs exogenously and information is complete, the long term employment relationship is preferred by the risk adverse workers. This implies that firms must implement a screening process when the information is asymmetric. We show that the optimal separating contract (an ascending wage profile) distorts the allocation of the workers who will retire later (the 'good' workers) in order to prevent the workers who will retire early (the 'bad' workers) from applying for these jobs. Secondly, we endogenize the retirement decision by considering two cases: an ex ante or ex post heterogeneity. In these two cases, we show that a separating equilibrium always exists, whereby good workers accept an ascending wage profile in order to make themselves differentiate from the 'bad' workers. These asymmetries in the information lead to an excess of retirement compared to the full information economy. Finally, in the case of ex post heterogeneity, we are able to show that the employment rate is unambiguously lower.

JEL Classification: D82, D86, J14, J26, J64

Keywords: competitive search equilibrium, separating equilibrium, retirement

Corresponding author:

Sheng $\mathrm{Bi}$

CES-Centre d'Economie de la Sorbonne

Maison des Sciences Economiques

106-112 boulevard de l'Hôpital

75647 Paris Cedex 13

France

E-mail: brbisheng@gmail.com

\footnotetext{
* We thank J.O. Hairault, D. Cohen, A. Cheron, E. Bernhard, R. Ranciere, and the participants of the Paris 1 macro workshop, the economic theory seminar at the University of Bielefeld, the PSE Macro retreat in Paris (ENS), Vienna QED 2013, Lyon T2M 2013 for fruitful discussions on this version of the paper.
} 


\section{Introduction}

The basic message of [the Phelps volume published in 1970] was that one could and should consider the [labor market] problems as the outcomes of market behavior of individual agents who act in their own interests as best they can in a market environment characterized by uncertainties and incomplete information. Mortensen (2010)

Since Phelps (1970), the search and matching frictions are presented as typical departures from the Walrasian theory of the labor market. They allow economists to account for the trading externalities, linked to the costly processes of co-ordination and information incompleteness (Diamond-Mortensen-Pissarides model). But the competitive search equilibrium leads to reducing the distance between the matching model and the Walrasian paradigm: a decentralized market can internalize the search externality, leading to an efficient equilibrium (Moen (1997)). In this paper, we re-introduce informational incompleteness in a competitive search environment to account for the inefficiency of the labor market allocation. If workers are heterogenous, the search frictions can lead the employers to sort them, since the ex-post returns for the firms are heterogeneous, even if the costs of posting a vacancy are homogenous. In competitive search equilibrium, the information on these ex-post matching returns is perfectly observable. Thus, an optimal segmentation occurs at the equilibrium: the 'good' and 'bad' workers are attracted to specific markets. This leads to the conventional view that the market gives optimally more chances to 'good' workers: the segmentation process is applied to the less profitable workers. For example, if an employer expects that an older worker has a higher probability of leaving the firm (retirement risk), it would be optimal to discriminate against these workers ${ }^{1}$ at the hiring stage. One may then have the tendency to believe that the cost associated with this risk of early retirement is borne by workers with the shorter horizon on the labor market, the 'optimal discrimination' being borne by these 'bad' agents.

If we explicitly introduce informational asymmetry, our paper shows that this 'simple' story of the competitive search equilibria is not robust: the labor market allocation is inefficient. We show, in several contexts with informational friction, that even if the separating equilibrium exists, the 'good' workers suffer from distorted contracts, contrary to the 'bad' workers. On a labor market with search frictions, if the contract is posted ex ante and if the firm commits, the one who has intended to hire 'good' workers must propose distorted contracts to discourage 'bad' workers from applying. This situation happens because the firms sink more virtual cost ex ante if they expect to meet a 'good' worker, generating a larger surplus. Thus, given this commitment via the hiring strategy, the employers want to avoid meeting undesirable workers. Because a 'good' worker generates a high surplus, it is possible for the firm to sacrifice part of it for the screening process. Hence, a sorting mechanism will be such that the 'bad' workers (the workers who prefer to retire sooner) receive

\footnotetext{
${ }^{1}$ Similarly, a process of discrimination may exist against women who present a maternity risk, which leads to forecasting more frequent rotations for them.
} 
non-distorted contracts, whereas the 'good' workers (the workers who prefer to retire later) receive distorted contracts. With these contracts, the labor market will be endogenously segmented, but this segmentation is suboptimal for the 'good' workers. In this sense, even if the discrimination process ${ }^{2}$ is directed 'against' the bad workers, its induced cost is 'paid for' by the good workers, i.e. the workers having the intrinsic incentive to work longer. Thus, this paper proves the existence of segmented labor market equilibria when information is asymmetrical, and discusses their positive and normative implications. ${ }^{3}$.

We think that our analysis is particularly well suited for the study of the labor market segmentation according to the 'social' age of the workers. By 'social' age, we refer to the horizon before the retirement age allowing workers to reach a pension at the full-rate. Many empirical studies (e.g. Gruber and Wise (1999) or Hairault, Langot and Sopraseuth (2010) on French data) show that when a worker can have a full pension, his probability of quitting his current job is very high. A worker may possess more information concerning the main determinants of his horizon (his expected retirement age), compared to her/his employer, since the employer needs to know the whole career of the employee in order to compute it. Thus, we are in a classical asymmetric information framework. The bad workers are the workers having a short horizon, whereas the good workers are the ones with a long horizon. As shown in Menzio, Telyukova and Visschers (2012) or Hairault, Langot and Zylberberg (2012), this heterogeneity of the horizon among workers leads firms to invest more in the labor market directed at the young workers, with the expected profit per job being greater. ${ }^{4}$ In these last two papers, the horizon of the workers is perfectly observable by the firms, ensuring the existence of a directed search equilibrium. Thus, we extend the study of the directed search equilibria where non-stationarity is induced by a retirement age, or more generally by an irreversible non-participation decision.

In the first part of the paper, we present a basic model where the retirement age is exogenous, but not perfectly observable by the firms. Thus, we are dealing with an asymmetric information problem, where ex ante, there are two types of workers, the ones who retire sooner and the others who retire later. We show that there always exists a separating contract, supporting the directed search equilibrium. This contract is characterized by a distortion of the wage profile afforded by the good workers: in the labor market segment of the good-type workers, the posted wage profile is age-increasing as a direct consequence of the incentive compatibility constraint, whereas, for the segment of the bad workers, there are no-distortions (flat wage rate). This suggests that the lack of information concerning

\footnotetext{
${ }^{2}$ We say the 'bad' workers are discriminated against in the sense that their expected utility from search is less than proportional compared to the good workers. We do not mean that the firms always prefer hiring bad workers to good workers. Firms are actually ex-ante identical, and indifferent to posting long term or short term contracts.

${ }^{3}$ We abstract from the case of the undirected matching technology which introduces additional trade externalities as discussed in Cheron, Hairault and Langot (2011 and 2013)

${ }^{4}$ Even if age discrimination is prohibited, advertising for a job vacancy can specify some individual characteristics related to age-differences. It is difficult to prove that these practices are an age-discriminatory process. Thus, as emphasized by Neumark (2001), we observe discrimination against older workers. As in our model, these papers give an explanation for this phenomenon.
} 
the worker's horizon leads to sub-optimal welfare of the workers accepting a priori to work longer.

Nevertheless, the retirement decision is endogenous: does the distortion of the wage contract have an impact on the decision to retire? The second part of the paper shows how the wage contract induces additional distortion on this extensive margin of the labor market. Indeed, the retirement decision depends crucially on the workers' outside options at the end of their life cycle. In particular, prior to becoming a senior, workers have heterogeneous working conditions, leading to a heterogeneity in the wealth and/or health distributions, and thus, in the value of leisure at the end of the life cycle. These worker-specific experiences may explain heterogeneity in the retirement age among ex ante identical individuals (see e.g. Cutler, Meara and Richards-Shubik (2011) for empirical evidences). Workers can be aware of this heterogeneity before (ex ante heterogeneity) or after (ex post heterogenity) the matching process. We analyze these two types of heterogeneity. The first one accounts for the possibility that the workers can compute their SS wealth, whereas firms do not have access to this information set. The ex post heterogeneity accounts for the case of shocks at the end of the life cycle (health or wealth shocks), not observable for the firms. First, we show that the optimal contracts lead to introducing wage distortions (characterized by an age-increasing wage profile) on the labor market for the good workers, for both types of heterogeneity, as in the case of exogenous separation. In the case of ex ante heterogeneity, the new result is that the equilibrium retirement threshold is lower than in an economy with full information: the less transparent is the SS system, the greater the number of workers that choose to retire. With ex post heterogeneity, we also show that not only do more workers choose to retire early, but the hiring rate of the workers who want to work for two periods (the 'long-horizon' or the good workers) is lower than in the full information case. Thus, the underemployment of the older worker is reinforced by a lower incentive to hire long-term contract workers, at least when the wage contract leads to a separating equilibrium.

Our paper is in the line of the seminal contribution from Salop and Salop (1976), who consider risk-neutral employees holding private information on their exogenous probability of leaving the job. From the firm's point of view, if some workers leave their jobs unexpectedly, another worker can be found, but the firm must pay a turnover cost, linked to the training costs. For the sake of minimizing the turnover costs, firms will prefer to hire only workers who have lower quit rates. They propose a compensation policy where employees are asked to make an up-front payment at the beginning of the employment relationship, which will be refunded gradually in the subsequent periods, conditional on their stay with the firm. Workers with a higher quit probability choose not to apply to firms with this contract offer, since they expect that they will have a low probability of receiving the repayments in the future. A self-selection mechanism is thus induced: agents truthfully reveal their private information by their market behavior.

However, it transpires that the results from Salop and Salop are not robust enough: if workers are risk-averse, and if firms are risk-neutral on a competitive market with a freeentry condition, the Salop and Salop model immediately collapses to share the same problem with the Rothschild and Stiglitz (1976) model (RS). In this context, there may exist no 
equilibrium in such a competitive market, when the fraction of bad workers is sufficiently low in the economy. Indeed, the risk aversion leads to age-increasing wage profiles implying a lower utility for the good workers, whereas the absence of a free-entry condition allows the firms to choose some profitable deviations that attract the good workers, given their convex indifference curves and under the single-crossing condition. As shown in Guerrieri, Shimer and Wright (2010) (GSW), the introduction of a bilateral matching process $\grave{a} l a$ Diamond-Mortensen-Pissarides (DMP $)^{5}$ ensures that the separating equilibrium can always be achieved. Indeed, with respect to a competitive environment à la RS, the competitive search equilibrium introduces a new endogenous variable (the market tightness) summarizing the value attached to the entry strategy. Nevertheless, we lose flexibility by introducing the restriction that matching is bilateral - each principal can serve at most one agent ex post, whereas in RS, each principal can serve the total population. This trading restriction acts as a sort of capacity constraint that plays the crucial role in resolving the RS non existence problem: when agents are not able to obtain a contract with probability 1 , they engage themselves actively in a subgame to maximize their expected payoff related to optimal search. At the limit, when the numbers of principals and agents tend to infinity, any pooling deviation is proved to be unprofitable. Thus, the meeting probabilities (derived from the market thickness) act as prices, which adjust endogenously to clear the market. In contrast, the RS equilibrium notion allows positive profit in the equilibrium. Thus, the principal can consider some deviations from an allocation with an arbitrary trading probability that doesn't clear the market (for example, via a free entry condition) but still belongs to the set of equilibria. ${ }^{6}$ In order to account for the separation costs, we extend the GSW framework by introducing a multiple-period model. In the last part of the paper, where we account for the endogenous retirement choices with ex-post heterogeneity, we also extend the Guerrieri's results (2008). The crucial difference between our model and that of Guerrieri (2008) comes from the fact that the heterogeneity matters inside and outside the firm in our case, whereas for Guerrieri, it matters only inside the firm. Indeed, for Guerrieri, the outside options are a homogeneous earning associated with the unemployment state, whereas for us, there is a distribution of the outside options necessary to describe the heterogeneity in the retirement values. We thus modify the techniques developed in Guerrieri (2008) to solve the equilibrium of our model.

The paper is organized as follows. We present the competitive search equilibrium of a model with exogenous retirement choices in Section 2. In Section 3, we introduce endogenous retirement choices by taking into account ex ante heterogeneity in the retirement earnings

\footnotetext{
${ }^{5}$ We restrict our analysis to the competitive search equilibrium. This allows us to only focus on the distortions induced by the asymmetric information. Thus, our search equilibrium is in the line of the model presented in Cao and Shi (2000), Burdett, Shi and Wright (2001), Shi (2002) and (2006). Note that Kirchers and Galenianos (2012) show that when the number of agents in the economy tends to infinity, the equilibrium converges to the competitive search ones, where a single firm's action will have insignificant effects on the market price.

${ }^{6}$ When they comment on the RS results, Guerrieri, Shimer and Wright (2010) observe that "Because the trading probabilities (or prices) are not restricted by the market, the set of potential deviations is enlarged, and this potentially contributes to non-existence of equilibrium."
} 
and we show that the mechanism design leads to a lower employment rate of the older workers. We then test for the robustness of this result when heterogeneity is observed only ex post by the workers. This is done in Section 4. Section 5 concludes.

\section{Competitive search with exogenous retirement}

Consider a 2-period economy with search friction. There is a fixed quantity of workers, and a quantity of firms, the number of which is variable and to be determined in the equilibrium. All workers start as unemployed. They get hired by a firm through a job-search process. We assume that an employed worker may leave the firm before the termination of the employment relationship with certain probability, because she may retire early for exogenous reasons ${ }^{7}$. Following Salop and Salop (1976), we focus on the case where the workers' heterogeneity comes from their exogenous probability of entering retirement in the 2 nd period. There are two possible types of workers ${ }^{8}$ : a fraction $\alpha$ are willing to work for 2 periods with probability $p_{H}$, called type " $H$ "; the rest, with fraction of $(1-\alpha)$, are type " $L$ " workers, who will enter the second periods with probability $p_{L}$, with $p_{H}>p_{L}$.

All firms are ex ante identical. In order to start production, each has to create a vacancy in the labor market, and then announce wages in hopes of getting matched with a worker. A sunk cost $C$ is induced for the creation of the vacancy. ${ }^{9}$ When an employer hires a worker, the match produces $y$ per period. We assume that firms and workers share the same subjective discount rate $\beta$.

There are matching frictions. We define $q$ to be the tightness of the labor market, i.e. the worker/firm ratio. ${ }^{10}$ The hiring probability for the firms is $H(q)$, while $F(q)$ denotes the workers' job finding rate. As is usual in the matching model, we assume

- the constant return to scale relationship $H(q)=q F(q)$;

- $F(q)$ the workers' job finding rate is decreasing and concave in $q$, the number of workers per firm, i.e. $F^{\prime}(q)<0$ and $F^{\prime \prime}(q)<0$;

- $H(q)$ the firms' hiring probability is increasing and concave in $q$, i.e. $H^{\prime}(q)>0$ and $H^{\prime \prime}(q)<0$;

- The elasticity of firms' hiring probability is a decreasing function in $q$ and between $(0,1)$, i.e. $\epsilon^{\prime}(q)=\left[\frac{H^{\prime}(q)}{H(q) / q}\right]^{\prime}<0$ and $\epsilon(q) \in(0,1)$.

\footnotetext{
${ }^{7}$ It would be useful to consider $p$ as a combination of the rate of stay and the rate of non-firing.

${ }^{8}$ Since introducing more types does not alter the main results, for the ease of exposition we stick to this case and refer interested readers to GSW (2010) for many discrete types.

${ }^{9}$ Following Acemoglu and Shimer (1999), we make use of the concept of submarket, where each firm, although ex ante homogeneous, will choose which type of agents to attract. Implicitly, we rule out the case that a firm may post at the same time contracts to attract both types of workers as in Shi (2002) and Shi (2006).

${ }^{10}$ In terms of directed search, the queue length is the expected number of applicants from a job seeker's perspective, as in Acemoglu and Shimer (1999).
} 
This wage posting game has three stages: (i) wage posting stage, where firms announce wages; (ii) job search stage, in which workers observe the posted wages, and choose where to apply; (iii) production stage, where the workers who get matched with firms produce, and payoffs are realized. Competitive search could be understood as directed search in a large economy, in the sense that when the number of agents tends to infinity, individual deviations are not able to alter the expected payoff received from the market. Galenianos and Kircher (2012) demonstrated this result.

\subsection{The competitive search equilibrium under full information}

In this section, we will describe the benchmark model, and use a particular example to show that workers are better off if hired in a long-term employment relationship.

Workers. With full information, two types of workers search respectively in different submarkets opened to them. These two submarkets are indexed according to their types, i.e., $H$ or $L$. At the beginning of the first period, each worker enters her submarket to search for a job; when she finds a job, she will work for two periods straight, with a probability $p_{H}\left(p_{L}\right)$ that she would actually remain in the firm in the second period; however, when she fails to find a job in the first period, she could search again at the beginning of the second period. Using $p$ (where $p$ stands for either $p_{H}$ or $p_{L}$ ) to denote the probability that the worker will stay, the worker's expected utility could be written in the following way:

$$
\begin{aligned}
U_{I I}(p) & =F\left(q_{I I}\right)\left[u\left(w_{I I, 1}\right)+\beta p u\left(w_{I I, 2}\right)\right]+\left(1-F\left(q_{I I}\right)\right)\left[u(z)+\beta p U_{I}\right] \\
\text { where } & \\
U_{I} & =F\left(q_{I}\right) u(w)+\left(1-F\left(q_{I}\right)\right) u(z)
\end{aligned}
$$

where the subscripts $I$ and $I I$ denote respectively the periods 'one' and 'two' of the contract. If a particular worker of type $p$ cannot find a job in the first period, she would search again in the second period, but has only a horizon of one period, allowing her to obtain a contract for one period $(I)$. Finally, z could be regarded as the utility derived from home production.

Firms. Ex ante identical firms should choose which submarket to enter. This implies that each firm can only attract one type of worker at most. ${ }^{11}$ The profit of firms is written as follows, where the first line is the profit for a firm contracting with a $I I$-period worker, and the second line is the profit for a firm contracting with a $I$-period worker:

$$
\begin{aligned}
\pi_{I I}(p) & =H\left(q_{I I}\right)\left[\left(y-w_{I I, 1}\right)+\beta p\left(y-w_{I I, 2}\right)\right]-C \\
\pi_{I} & =H\left(q_{I}\right)\left(y-w_{I}\right)-C
\end{aligned}
$$

\footnotetext{
${ }^{11}$ If firms are allowed to attract both types of workers at the same time, firms are showing a portfolio problem where workers with higher value of $p$ are always hired in preference to the workers with lower value of $p$. The problem is more complex, and we refer interested readers to Shi (2006) for more details.
} 
Definition of Competitive Search Equilibrium: A competitive search equilibrium is a set of wage profiles $w^{*}(p)=\left\{w_{I I, 1}^{*}(p) ; w_{I I, 2}^{*}(p)\right\}$, together with a function $q^{*}(p)=q\left(w^{*}(p)\right)$ and utility levels $U^{*}(p)$ for $p \in\left\{0, p_{L}, p_{H}\right\}$ that satisfies the following conditions:

(1) employers' profit maximization and free entry,

$$
H\left(q_{I I}^{*}(p)\right)\left[\left(y-w_{I I, 1}^{*}(p)\right)+\beta p\left(y-w_{I I, 2}^{*}(p)\right)\right]-C \leq 0
$$

(2) workers' optimal job application,

$$
U_{I I}^{*}(p) \geq F\left(q_{I I}^{*}(p)\right)\left[u\left(w_{I I, 1}^{*}(p)\right)+\beta p u\left(w_{I I, 2}^{*}(p)\right)\right]+\left(1-F\left(q_{I I}^{*}(p)\right)\right)\left[u(z)+\beta p U_{I}^{*}(p)\right]
$$

where $U_{I I}^{*}(p)$ is given by

$$
U_{I I}^{*}(p)=\max _{w(p)}\left\{\begin{array}{l}
F\left(q_{I I}(w(p))\right)\left[u\left(w_{I I, 1}(p)\right)+\beta p u\left(w_{I I, 2}(p)\right)\right] \\
+(1-F(q(w(p))))\left[u(z)+\beta p U_{I}(p)\right]
\end{array}\right\}
$$

The solution is characterized by the following equations: for $p \in\left\{0, p_{L}, p_{H}\right\}$, we have

$$
\begin{aligned}
w_{I I, 1}^{*}(p)=w_{I I, 2}^{*}(p) & =w_{I I}^{*}(p) \\
H\left(q_{I I}^{*}(p)\right)(1+\beta p)\left(y-w_{I I}^{*}(p)\right) & =C \\
\frac{1-\epsilon_{p}\left(q_{I I}^{*}(p)\right)}{\epsilon_{p}\left(q_{I I}^{*}(p)\right)} & =\frac{y-w_{I I}^{*}(p)}{\frac{1}{u^{\prime}\left(w_{I I}^{*}(p)\right)}\left[u\left(w_{I I}^{*}(p)\right)-\frac{1}{1+\beta p}\left(u(z)+\beta p U_{I}^{*}(p)\right)\right]}
\end{aligned}
$$

where $\epsilon(q)$ denotes the elasticity of the firms' hiring probability with respect to the queue length. Leaving aside the conditions of free entry, the first order condition could be interpreted in the following manner: the LHS gives the relative contribution of firms and workers to the total number of matches created, as the ratio between the firms' search effort to the workers' search effort, whereas the RHS gives the surplus ratios between firms and workers, in units of goods (the surplus of the workers is thus corrected by the marginal utility).

In order to capture the idea of the most important results, we consider a particular pair of parameter values by setting $p_{H}=1$ and $p_{L}=0$. The two types of workers are the type- $I I$ workers, who work for sure two $(I I)$ periods, and the type- $I$ workers, who will work only for one $(I)$ period.

Proposition 1. The competitive search equilibrium is characterized by:

- The optimal level of per period wage is such that $w_{I I}^{*}>w_{I}^{*}$

- The optimal level of expected queue length is such that $q_{I}^{*}>q_{I I}^{*}$

- The increment of the wages payment increases more slowly than the enhancement of productivity: $(1+\beta) w_{I I}^{*}-w_{I}^{*}<\beta y$. 


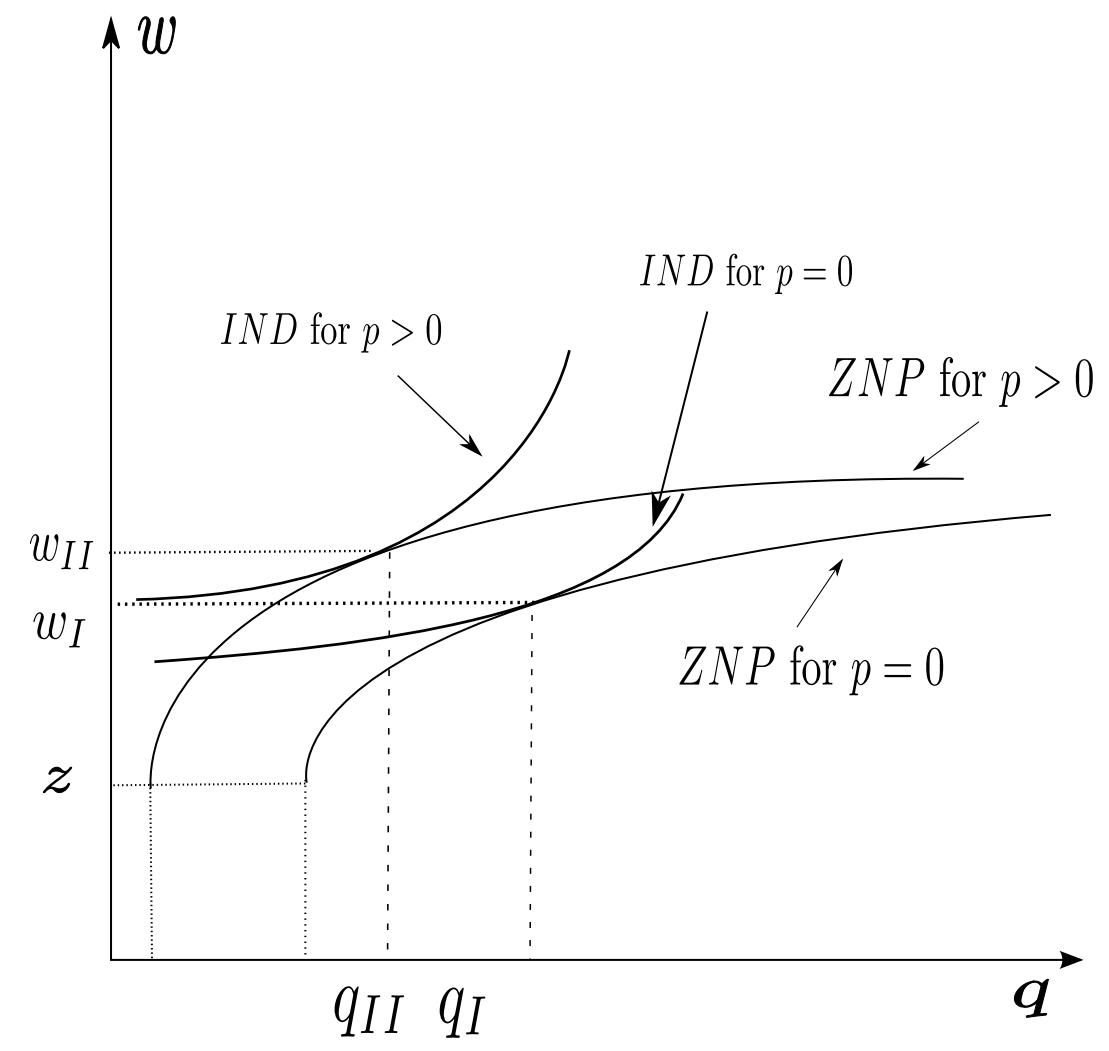

Figure 1: Labor market equilibrium with perfect information

\section{ZNP: Zero Net Profit condition}

$I N D$ : Indifference curve

\section{Proof. See Appendix A.}

This proposition states that not only do the type $I I$ workers earn higher per-period wages, but also they are matched more often compared to the workers engaged in short-term employment relationships (see Figure 1). These two observations lead us immediately to the following proposition:

Proposition 2. The workers are better off in a long-term employment relationship, than in a short-term repeated contract, in terms of both ex ante and ex post welfare.

Proof. See Appendix B.

It is also interesting to notice that, although firms pay the same entry $\operatorname{cost} C$ on each submarket, the effective cost, defined as $\frac{C}{H(q)}$, is obtained by dividing by the average duration of the search, the unit cost. The inequality $q_{I}>q_{I I}$ coincides with our intuition that in order to earn higher ex post surplus, the firm which posts type $I I$ contracts understands that they should be willing to wait longer till such a worker appears.

With perfect information, we have established that the workers are better off in a longterm employment relationship. Although all different types offer the same quality of labor, 
type- $I$ workers receive lower wages and suffer from a lower expected utility. It is this situation which generates incentives for the type- $I$ workers to visit the submarket for the type- $I I$ workers, if information is not perfectly shared. Thus firms which post long-term employment contracts and are uninformed about the workers' types, may suffer losses if they hire a type- $I$ worker, despite the fact that they have incentives to hire a type- $I I$ worker. We are thus led to consider the possibility for the firms to manipulate wage profiles to induce a self-selection process among the workers, such that no workers will misrepresent their types.

\subsection{The allocation under asymmetric information}

In the previous subsection, we have shown that type- $I$ workers have an incentive to cheat, because they find that higher expected utility could be obtained if they send applications to a market where firms want to hire a type- $I I$ worker. Now the essential question is how to prevent this situation from happening such that a separating equilibrium can be achieved. Intuitively, in order to discourage the bad workers from joining the submarket for the good workers, the firms may consider an alternative wage profile to discourage the bad workers from applying. A standard way is to introduce an incentive compatibility constraint, by which the type- $I$ worker should find it unattractive to pretend to be a type- $I I$ worker.

We come back to the general case where the economy is populated with two types of individuals distinguished by $p_{H}$ and $p_{L}$ respectively. The index $A I$ denotes the optimal allocation under asymmetrical information. We make some modifications on the notations: now the type $I I$ workers could be either of low $L$ or $H$ types. The optimization program is written is follow:

$$
\begin{aligned}
U_{H}^{A I}= & \max _{\left\{q, w_{H, 1}, w_{H, 2}\right\}}\left\{F(q)\left[u\left(w_{H, 1}\right)+\beta p_{H} u\left(w_{H, 2}\right)\right]+(1-F(q))\left(u(z)+\beta p_{H} U_{I}\right)\right\} \\
\text { s.t. } & H(q)\left[y-w_{H, 1}+\beta p_{H}\left(y-w_{H, 2}\right)\right] \geq C \\
I C \text { constraint } & F(q)\left[u\left(w_{H, 1}\right)+\beta p_{L} u\left(w_{H, 2}\right)\right]+(1-F(q))\left(u(z)+\beta p_{L} U_{I}\right) \leq U_{L}
\end{aligned}
$$

where

$$
\begin{array}{ll}
U_{L}= & \max _{\left\{q, w_{L, 1}, w_{L, 2}\right\}}\left\{F(q)\left[u\left(w_{L, 1}\right)+\beta p_{L} u\left(w_{L, 2}\right)\right]+(1-F(q))\left(u(z)+\beta p_{L} U_{I}\right)\right\} \\
\text { s.t. } & H(q)\left[y-w_{L, 1}+\beta p_{L}\left(y-w_{L, 2}\right)\right] \geq C
\end{array}
$$

and

$$
\begin{array}{ll}
U_{I}= & \max _{\{q, w\}}\{F(q) u(w)+(1-F(q)) u(z)\} \\
\text { s.t. } & H(q)[y-w] \geq C
\end{array}
$$

This economy is an extension to the theoretical context proposed by Guerrieri, Shimer and Wright (2010). And the following result could be achieved:

Proposition 3. In our economy, the separating equilibrium always exists. 
Proof. It suffices to check that 3 mild assumptions proposed in Guerrieri, Shimer and Wright (2010), which are common in contract literature, are satisfied, so that it could be verified that the separating equilibrium always exists. (In Appendix C, the verification of these assumptions in our context is shown.

Whereas the Salop and Salop (1976) economy under a competitive market with search friction is not immune to the nonexistence problem highlighted in Rothschild and Stiglitz (1976) when the contact probabilities are exogenous ${ }^{12}$, the above proposition suggests that the separating equilibrium exists when the trading probabilities are endogenized. This is due to the fact that by considering matching, some sort of capacity constraint is introduced: one principal can at most get matched with one agent. This in fact corresponds to one of the ways proposed in the literature for solving the RS problem. We now turn to the properties of this equilibrium.

Proposition 4. Under asymmetric information, the equilibrium allocation is such that:

- in the submarket of type- $p_{L}$, we have $q_{L}^{A I}=q_{L}^{*}$, and $w_{L, 1}^{A I}=w_{L, 2}^{A I}=w_{L}^{*}$;

- in the submarket of type- $p_{H}$, we have $w_{H, 1}^{A I}<w_{L}^{*}<w_{H}^{*}<w_{H, 2}^{A I}$;

- The type- $p_{H}$ workers are worse off in terms of expected utility, compared to the fullinformation case: $U_{H}^{A I}<U_{H}$;

- The type- $p_{L}$ worker receives the same expected utility: $U_{L}^{A I}=U_{L}<U_{H}^{A I}$.

Proof. See Appendix D.

In the presence of asymmetric information, separating equilibrium is achieved by increasing the wage of the type- $H$ worker with his tenure in the firm. This wage profile discourages the type- $L$ workers from applying, because the type- $L$ workers become aware that tomorrow they have a lower probability of staying, thus choosing this non-smoothed wage profile makes them receive a lower expected utility compared to the smoothed wage payment which features first best. In contrast, the type- $H$ worker has a higher probability of remaining at work tomorrow. Thus, she is willing to sacrifice some wages today, in exchange for higher earnings tomorrow ${ }^{13}$. In exchange, they obtain a higher utility than the type- $L$ workers.

Salop and Salop (1976) describe the same mechanism to induce self-selection. They consider a so-called Two-Part Wage (TPW) requiring that a new employee at the matching stage pays the firm an entrance fee of $D_{1}$, in return for which she will receive $w+D_{2}$ in the subsequent periods. In the equilibrium, the worker should pay her own turnover costs. This is equivalent by saying that this worker garantees that she will pay for the consequences. Our wage profile (Proposition 4) could also be interpreted in a fashion similar

\footnotetext{
${ }^{12}$ We have proved these results in a separate work (available upon request), and also the fact that the separating equilibrium may not exist when the fraction of bad types is sufficiently small.

${ }^{13}$ It is also interesting to point out that with multiple types, it is easy to verify that for the best worker, the degree of the steepness of her wage increase augments with the number of types.
} 
to Salop and Salop (1976). Recall that the free-entry condition in the presence of asymmetric information specifies $\frac{C}{H\left(q_{H}^{A I}\right)}=y-w_{1, H}^{A I}+\beta p_{H}\left(y-w_{2, H}^{A I}\right)$, and in the absence of asymmetric information $\frac{C}{H\left(q_{H}\right)}=y-w_{H}+\beta p_{H}\left(y-w_{H}\right)$. We could thus define the following difference: $D_{1}=w_{H}-w_{1, H}^{A I}>0$ and $D_{2}=w_{2, H}^{A I}-w_{H}>0$. Salop and Salop (1976) obtain the equality $\frac{D_{1}}{D_{2}}=\beta p_{H}$ (the self-selection ratio) at the equilibrium, due to worker risk-neutrality. In our context, under risk-aversion, the result becomes $\frac{D_{1}}{D_{2}}>\beta p_{H}$ if the following inequalities are satisfied $w_{H}+\beta p_{H} w_{H}>w_{1, H}^{A I}+\beta p_{H} w_{2, H}^{A I}>w_{L}+\beta p_{L} w_{L} \cdot{ }^{14}$ This would mean that the firms ask the workers to pay an amount of premium $D_{1}$ in order to insure themselves against the quit rate, and in case the worker stays tomorrow, the firm and the worker will be better off, the lower gap between $D_{1}$ and $D_{2}$ being governed by the demand of a smoother profile of wages. Thus, the risk-aversion puts a restriction on the inter-temporal transfers and the separating equilibrium may be Pareto inefficient when the fraction of bad workers is sufficiently small. ${ }^{15}$

Proposition 5. The separating equilibrium may be Pareto inefficient under certain particular parameter values.

Proof. See Appendix E.

If the share of the bad workers is small enough, the pooling allocation dominates the separating equilibrium, even though the pooling equilibrium never exists. Indeed, the optimization program of the pooling allocation approaches the optimization program for the type- $H$ workers in the full information case, implying that $w_{\alpha} \rightarrow w_{H}, q_{\alpha} \rightarrow q_{H}$ and thus the good workers will be better off. Given that the allocation under full information is such that $q_{H}^{*}<q_{L}^{*}$ and $w_{H}^{*}>w_{L}^{*}$, the type $L$-workers could be employed more often, receive higher wages with this constructed pooling allocation and thus will also be better off.

\section{Competitive search and retirement decisions}

In the previous section, we have considered retirement as an event which happens exogenously. In this section, we allow the agents to choose their retirement age. We study how this extensive margin can be manipulated by the optimal contract. The introduction of an outside option at the end of the life cycle (necessary to account for retirement choices) allows us to analyze how an incentive scheme distorts retirement choices.

There is a large literature on retirement choices: the main explaining factors for this labor market transition, after controlling for the usual observed heterogeneity, are the social security wealth, financial wealth or health. In this section, we propose a simple framework where the realizations of these state variables (the SS wealth, financial wealth and health)

\footnotetext{
${ }^{14}$ Unfortunately, we are not able to show these inequalities analytically, although we think it is the most likely case

${ }^{15}$ In Salop and Salop (1976),there is no efficiency gain from introducing this self-selection mechanism, because both workers and firms are risk-neutral.
} 
are not perfectly observed by the firms, whereas the workers have complete information on these characteristics at the time of the hiring (ex ante heterogeneity). For simplicity, we assume that each worker is characterized by a specific realization of these variables, which leads to a worker-specific retirement age. Because this information is not directly observed by the employer, firms must extract it by a mechanism.

In this context, a simple way to endogenize retirement choice is to introduce an outside option which is worker-specific. Thus, we assume that the worker's private information comes from the 'value' of the leisure to which she has access. Below a threshold, the low value of her leisure leads the worker to stay in the firm: she will then quit with probability 0. In contrast, a worker will quit with probability 1 if in the 2 nd period the utility of the leisure is strictly higher than the utility obtained if she stays in the firm. In this sense, individuals' decisions about quitting are 'endogenous'.

We distinguish two timings: in the first, each worker knows her characteristic when she meets a firm, whereas in the second, the information on her characteristic is revealed after the matching. In the first case, the asymmetry in the information is ex ante, whereas in the second, it is ex post.

\subsection{Ex ante heterogeneity, retirement choice and contracts}

Denote the threshold of the candidate equilibrium as $\hat{h}^{F I}$. We start by focusing on the following three possible situations:

- Situation 1: both are type-II, with home production levels $h_{1}<h_{2}<\hat{h}^{F I}$

- Situation 2: both are type-I, with home production levels $\hat{h}^{F I}<h_{1}<h_{2}$

- Situation 3: a type- $I$ and a type- $I I$ worker, with types $h_{1}<\hat{h}^{F I}<h_{2}$

where FI stands for 'full information', and the threshold $\hat{h}^{F I}$ is determined by

$$
U_{I}=U_{1 p}+\beta u\left(\hat{h}^{F I}+z\right)=U_{I I}
$$

which requires that $\hat{h}^{F I}$-worker to be indifferent about working or not in the 2 nd period (see Figure 2). ${ }^{16}$

With a continuum of values for $h$, these 3 situations comprise all possibilities. In situation 1 , the low value of $h$ for all the workers is such that all of them choose to stay in the labor market and retire after 2 periods (both types participate for two periods), whereas in situation 3, the high value of $h$ for all the workers is such that all of them only search in the first period and choose not to participate in period 2 (both types retire after 1 period). It could be shown that in both situations, the equilibrium is unique and the allocation

\footnotetext{
${ }^{16}$ Notice that in order to prove the existence of such a threshold level $\hat{h}^{F I}$, it is sufficient to verify that (1) the function $U_{I}(h)$ starts below $U_{I I}(h)$, and eventually finishes above $U_{I I}(h),(2)$ both $U_{I}(h)$ and $U_{I I}(h)$ are increasing functions.
} 


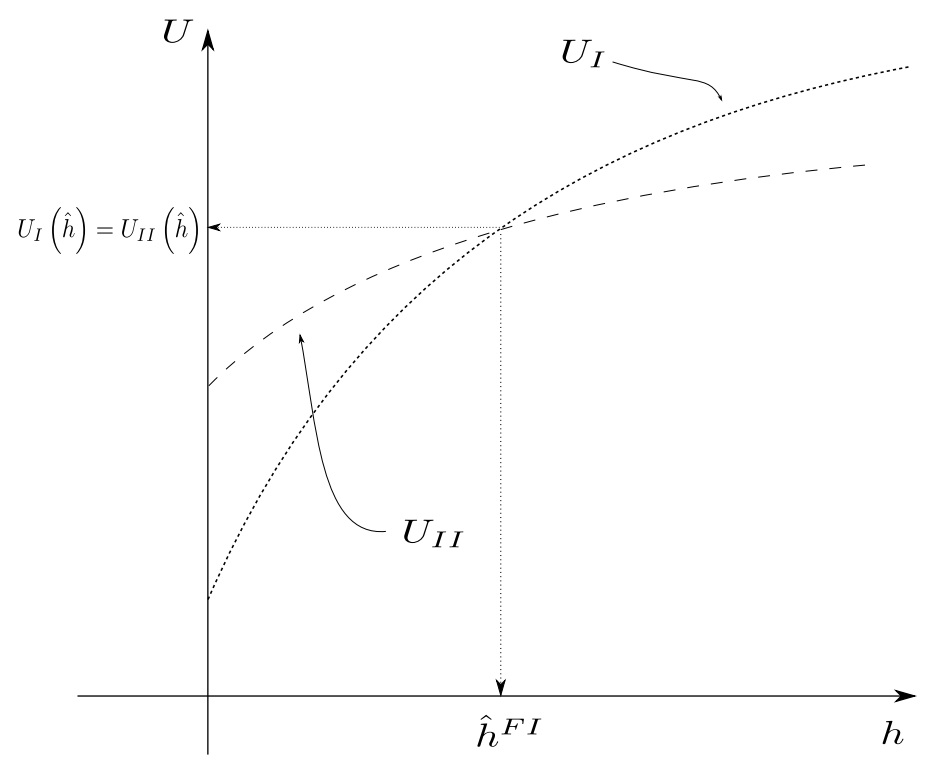

Figure 2: Existence of the threshold

reaches the first best: ex ante heterogeneity doesn't induce incentive problems. As in Section 2, the optimal contracts provided to two-period workers (those who have a low level of $h$ ) deliver higher expected utility relative to the optimal contracts provided to one-period workers ${ }^{17}$ (those who have higher values of $h$ ). Intuitively, when all the workers retire after 2 periods (situation 1), the distribution of the outside option changes the relative value of the employment, but not sufficiently to lead the agents to retire before $\hat{h}^{F I}$. Then, from the firms' perspective, there is no risk involved because all workers stay. The posted wage contract is thus flat and the hiring process is optimal. All the worker types work during all their life cycle, and there is no information problem. When all workers retire in period 1 (situation 2 ), as previously the optimal contract doesn't depend on $h$ because ex ante heterogeneity is irrelevant, and the higher value of expected utility is solely due to the higher value of home production level $h$.

Before entering into the exact analysis, we would like to mention one modification for the notations. In the previous section, the type-I job seekers are equivalent to those job seekers who only have the intention of working for one period. So the notation $U_{I}(h)$ was interchangeable when we mean a one-period job seeker who does not have a second period life and a type-I job seeker. As will be seen, this is not the case here. In this section, we use the notation $U_{1 p}$ to denote the utility of those who only have one period of life.

\subsubsection{Equilibrium with retirement age heterogeneity}

Now we turn to the remaining case where a type- $I$ worker and a type- $I I$ worker will be present: the situation 3. With imperfect information, we now first show that the type- $I$

\footnotetext{
${ }^{17}$ See Appendices $\mathrm{F}$ and $\mathrm{G}$ for the formal proofs.
} 


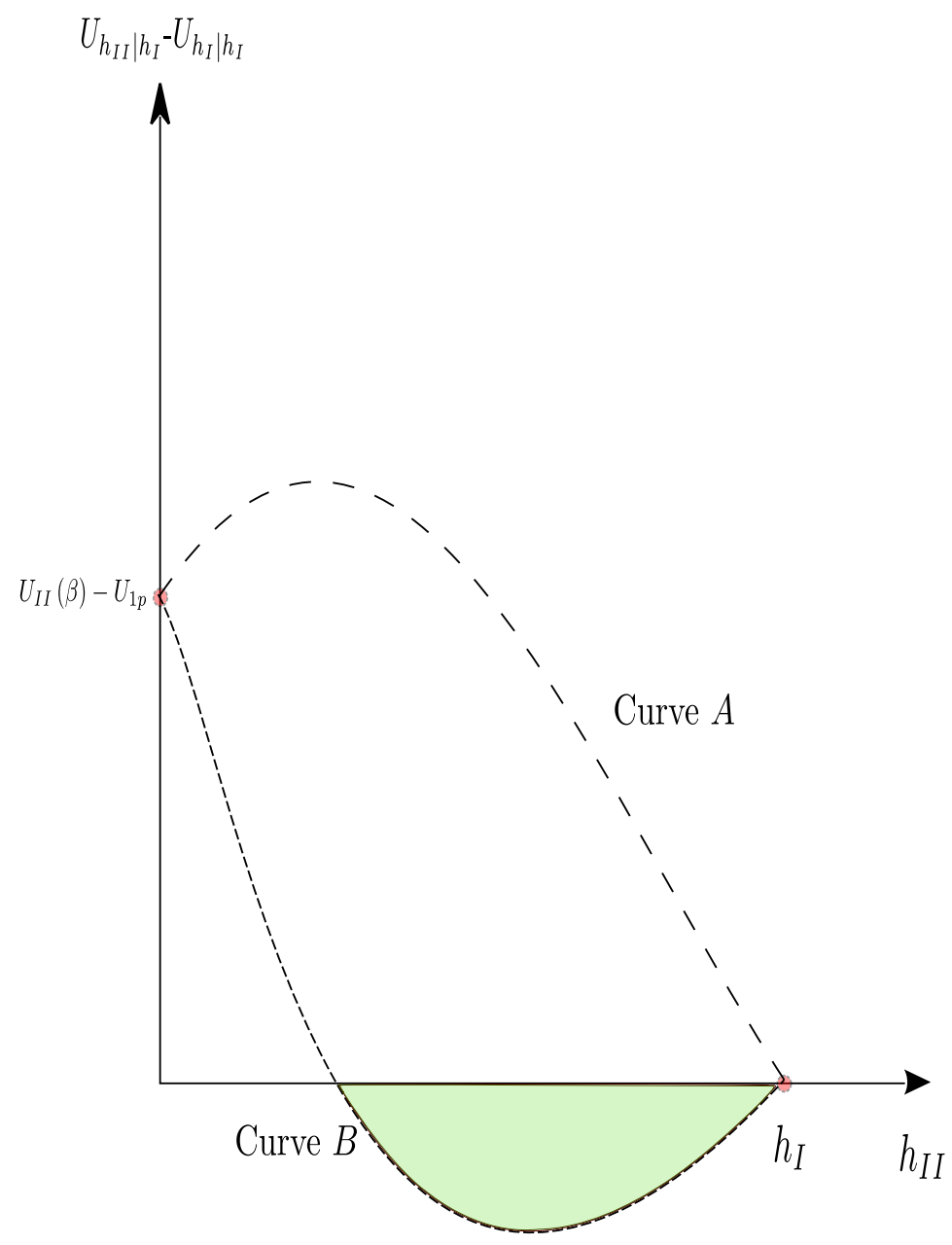

Figure 3: Misreporting brings higher utility

workers have an incentive to misrepresent themselves as type- $I I$ workers.

Proposition 6. Type-I workers may mimic type-II workers. A sufficient condition for this to happen is that $\frac{d^{2} w_{I I}}{d h_{I I}^{2}}<0$ and $\frac{d^{2} q_{I I}}{d h_{I I}^{2}}>0$, where $w_{I I}$ and $q_{I I}$ are respectively the equilibrium wage and queue length for type-II workers.

Proof. See Appendix H.

Figure 3 gives the intuition of the proposition. The region in light green is where misrepresenting one's type yields lower utility. Hence to ensure that type-I workers have an incentive to misrepresent their type, i.e. the gain from misreporting is always positive, it suffices that the utility difference from misreporting $U_{h_{I I} \mid h_{I}}-U_{h_{I} \mid h_{I}}$ is concave, which is ensured by $\frac{d^{2} w_{I I}}{d h_{I I}^{2}}<0$ and $\frac{d^{2} q_{I I}}{d h_{I I}^{2}}>0$.

Proposition 6 thus indicates that it is necessary for the firms to implement a mechanism allowing them to avoid the risk of hiring a worker with a short horizon for a job where the search costs can only be recouped by a worker with a long horizon. The optimization 
program is written as follows:

$$
\begin{aligned}
U_{h_{I I}}^{A I}= & \max F\left(q_{I I}\right) u\left(w_{I I, 1}\right)+\left(1-F\left(q_{I I}\right)\right) u(z)+\beta F\left(q_{I I}\right) u\left(w_{I I, 2}\right)+\beta\left(1-F\left(q_{I I}\right)\right) u\left(h_{I I}+z\right) \\
\text { s.t. } & \left\{\begin{array}{c}
H\left(q_{I I}\right)\left[y-w_{I I, 1}+\beta\left(y-w_{I I, 2}\right)\right] \geq C \\
F\left(q_{I I}\right) u\left(w_{I I, 1}\right)+\left(1-F\left(q_{I I}\right)\right) u(z) \leq U_{I}\left(h_{I}\right)
\end{array}\right.
\end{aligned}
$$

where the second inequality is an incentive compatibility constraint which makes the contract offered to type-II workers unattractive for type-I workers.

Proposition 7. The optimal contract is such that $w_{I I, 1}<w_{I I}^{F I}<w_{I I, 2}$ and $q_{I I}^{A I}<q_{I}^{A I}=q_{I}$.

Proof. See Appendix I.

The incentive contract introduces an age-increasing wage. More precisely, by setting $w_{I I, 1}<w_{I I}^{F I}<w_{I I, 2}$, the agents who would choose to retire early are discouraged from applying. We move now to the next proposition on the retirement threshold:

Proposition 8. The threshold of the pooling equilibrium is such that $\hat{h}^{A I}<\hat{h}^{F I}$.

Proof. By definition, we should have $U_{I I}^{A I}\left(\hat{h}^{A I}+z\right)=U_{I}\left(\hat{h}^{A I}+z\right)$ and $U_{I I}^{F I}\left(\hat{h}^{F I}+z\right)=$ $U_{I}\left(\hat{h}^{F I}+z\right)$. Now suppose that $\hat{h}^{A I} \geq \hat{h}^{F I}$. This implies that $U_{I I}^{A I}\left(\hat{h}^{F I}+z\right) \geq U_{I}\left(\hat{h}^{F I}+z\right)$, i.e., the type $\hat{h}^{F I}$ in the asymmetric information economy will not choose to retire. However, this in turn implies that $U_{I I}^{A I}\left(\hat{h}^{F I}+z\right) \geq U_{I}\left(\hat{h}^{F I}+z\right)=U_{I I}^{F I}\left(\hat{h}^{F I}+z\right)$, which is impossible, because we know $U_{I I}^{A I}<U_{I I}$ for any level of $h$.

At the equilibrium, the optimal contract reaches a separating equilibrium while retaining fewer people active at the end of the life cycle. This is a direct consequence of the retirement decision. As in the previous context, to achieve separating equilibrium, it is necessary to distort the contract of type- $I I$ workers. However, here an additional loss is induced: the worker who should have remained active chooses now to retire. Indeed the firm must discourage the undesirable workers (the short-horizon workers who behave as the long-horizon) from applying for the job posted for the workers who want to work for two periods (the "long-horizon"). However, this is done through firms' ex ante decisions in restricting the set of the workers who apply for long term contracts in order to screen the applicants.

By nature, when the risk from search is endogenously affected by the posted contract, the good (long-horizon) workers have to pay for the information rent, by receiving distorted allocation, which further decreases their expected utility, and leads them to choose early retirement. Hence, we observe that if the extensive margin of retirement is endogenized, the distorted wage offer operates through the extensive margin of search to lower the total labor supply when there is asymmetric information.

Importantly, this contrasts with the results of Guerrieri, Shimer and Wright (2011) where the separating contract leads to a rise of the intensive margin in the asymmetric information case. Nevertheless, in our dynamic context, even if the contract proposes an age-increasing wage, this cannot lead agents to postpone their retirement age because the screening process is done ex ante. This is not the case in Guerrieri, Shimer and Wright (2011) because the intensive margin can react immediately to the wage. 


\subsubsection{Efficiency}

We have arrived at the point of pondering whether the separating equilibrium we have just obtained may achieve the constrained efficiency. The main result established in this section is the following: unlike the baseline economy with exogenous retirement, the welfare with pooling allocation may or may not be Pareto dominant depending on the magnitude of the home production level. Specifically, the welfare may be either increasing or decreasing in the share of type- $I I$ workers in the total population. We show that under certain parameter values, the pooling allocation may still Pareto dominate the separating equilibrium. Furthermore, we point out that if the pooling allocation Pareto dominates then the threshold of the leisure value is higher than in the separating equilibrium. This implies an economy with early retirement: $\hat{h}^{A I}<\hat{h}^{\text {pooling }}<\hat{h}^{F I}$.

The optimal pooling allocation solves the following program:

$$
\begin{aligned}
U^{\text {pooling }}=\max \left\{\begin{array}{l}
F(q) u\left(w_{1}\right)+[1-F(q)] u(z) \\
+\alpha\left[\beta F(q) u\left(w_{2}\right)+\beta[1-F(q)] \max \left\{u\left(h_{I I}+z\right), U_{1 p}\right\}\right] \\
+(1-\alpha) \beta u\left(h_{I}+z\right)
\end{array}\right\} \\
\text { s.t. } \quad F(q)\left[y-w_{1}+\alpha \beta\left(y-w_{2}\right)\right] \geq \frac{C}{q}
\end{aligned}
$$

where $\alpha$ represents the proportion of the type- $I I$ workers in this economy; by the law of large numbers, $\alpha$ also captures the probability that the matched worker is of type- $I I$. This program is defined such that the fictitious representative agent's expected utility from search is maximized.

By definition of the pooling allocation, only one type of contract could be posted. In our economy, the posted contract is either $w$ for a duration of 1 period or $\left(w_{1}, w_{2}\right)$ which has a duration of 2 periods. To determine which type of contract would be posted at the equilibrium, it is crucial to find which type of contract will give the representative agent higher expected utility. Notice that the two following notions are equivalent:

a) At equilibrium, the 2-period (1-period) contracts will be posted.

b) The representative worker's welfare is increasing (decreasing) with respect to the share of type- $I I$ workers in the economy, i.e. $\alpha$.

As for the intuition, it suffices to notice that, when getting matched with a type- $I I$ (or type- $I$ ) worker with higher likelihood turns out to bring higher expected utility $\left(U^{\text {pooling }}\right)$, the employers would have incentives to create more 2-period (or 1-period) vacancies.

Thus, we examine under which conditions the expected utility $U^{\text {pooling }}$ increases/decreases with respect to $\alpha$. It turns out that it is the size of the home production of the type- $I$ worker $\left(h_{I}\right)$ that plays a crucial role in affecting the sign of $\frac{\partial U^{\text {pooling }}}{\partial \alpha}$. This observation leads to the following three propositions.

Proposition 9. Depending on the magnitude of $h_{I}, \frac{\partial U^{\text {pooling }}}{\partial \alpha}$ can be positive or negative; and a sufficient condition for $\frac{\partial U^{\text {pooling }}}{\partial \alpha}<0$ is $y<h_{I}+z$. 
Proof. See Appendix K.

How to understand this result? Specifically, why may the representative agent's welfare decrease with the fraction of type- $I I$ workers, when the level of $h_{I}$ is sufficiently large? Focusing on the expression of $\frac{\partial U^{\text {pooling }}}{\partial \alpha}$, which is obtained from the envelope condition, we find that it can be broken down into two parts:

$\frac{\partial U^{\text {pooling }}}{\partial \alpha}=\beta u^{\prime}\left(\hat{w}_{2}\right)\left\{\begin{array}{l}\overbrace{F(\hat{q})\left[\frac{\left[u\left(\hat{w}_{2}\right)-\max \left\{U_{1 p}, u\left(h_{I I}+z\right)\right\}\right]}{u^{\prime}\left(\hat{w}_{2}\right)}+\left(y-\hat{w}_{2}\right)\right]}^{\text {the joint gain from an additional period of production }} \\ +\underbrace{\frac{\max \left\{U_{1 p}, u\left(h_{I I}+z\right)\right\}-u\left(h_{I}+z\right)}{u^{\prime}\left(\hat{w}_{2}\right)}+0}_{\text {the loss from meeting a type-I worker, who quits at period } 2}\end{array}\right\}$

where the positive part represents the expected joint gains derived from an additional period of production, while the negative part ${ }^{18}$ represents the joint losses derived from a vacant post, which is caused by a premature termination of the employment relationship, in the case when the 2-period contract is proposed to a type- $I$ worker. The intuition then becomes clear: when the value of $h_{I}$ is large enough, all the firms find that the potential losses from creating 2period vacancies, which is subject to the risk of a premature termination of employment contract, may exceed the gains from doing so.

However, as shown in the Appendix, for mild values of $h_{I}$ and regular conditions on the utility functions, the positive part can dominate the negative part. In this situation, it will be in the firm's interest to create the 2-period vacancies. Hence, given a value of $h_{I}$, we have also made an informal proof of our previous remarks that the sign of $\frac{\partial U^{\text {pooling }}}{\partial \alpha}$ acts as a natural 'statistic' for the determination of the type of equilibrium contract.

Proposition 10. If $\frac{\partial U^{\text {pooling }}}{\partial \alpha}>0$, the separating equilibrium can be Pareto dominated by a pooling allocation, when the fraction of type-II workers is sufficiently large.

Proof. See Appendix L

As in Section 2, if the share of the type- $I$ workers is small enough, the pooling equilibrium dominates the separating equilibrium. Indeed, we can show one more time that the optimization program of the pooling allocation approaches the optimization program for the type-II workers in the full information case, implying that $w^{\text {pooling }} \rightarrow w^{F I}$ and $q^{\text {pooling }} \rightarrow q^{F I}$. In this case, both the good workers (type- $I I$ ) and the bad workers (type- $I$ ) will be better off in terms of expected utility compared to the separating equilibrium. The intuition behind this result is traditional: for the type- $I I$ workers, the collective cost from being screened (featured in a separating equilibrium), can be surpassed by the collective gain from agreeing to cross-subsidize the type- $I$ workers (featured in a pooling equilibrium). This can happen when the fraction of the type- $I$ workers is sufficiently low. Indeed, the separating equilibrium

\footnotetext{
${ }^{18}$ If the worker quits, then the firm obtains zero net surplus.
} 
leads firms to bear higher hiring costs per worker in the submarket of type- $I I$ workers. This is more than compensated for if the gap from this strategy and the pooling allocation, which leads to hiring costs at their average levels, is large. It is intuitive that the gap reduces with the proportion of high quality workers (type- $I I$ workers). Obviously, this strategy can be welfare improving because the separating equilibrium is only a second best: the firms distort the optimal allocation of the good workers in order to sort. Thus, if the gains from the sorting are low because the large majority of the agents are good workers, this bias is wasteful with respect to its marginal gain, even if we look at the welfare level.

Proposition 11. The threshold of the pooling equilibrium is such that $\hat{h}^{A I}<\hat{h}_{\alpha \rightarrow 1}^{\text {pooling }}<\hat{h}^{F I}$, given that $\frac{\partial U^{\text {pooling }}}{\partial \alpha}>0$.

Proof. See Appendix M

We note that the ranking of the equilibrium threshold levels is in fact consistent with the Pareto ranking of different types of equilibrium: The intuition is that this ranking of

\begin{tabular}{|c|c|c|c|}
\hline asymmetric & information & & full information \\
\hline rating equilibrium & $\prec \quad$ pooling equilibrium & $\prec$ & separating equilibrium \\
\hline$\hat{h}^{A I}$ & $\hat{h}_{\alpha \rightarrow 1}^{\text {pooling }}$ & $<$ & $\hat{h}^{F I}$ \\
\hline
\end{tabular}

the threshold levels is in fact a translation of the workers' expected utilities featured under different types of equilibrium. It is more clear if we come back to the indifference equation which pins down the threshold home production level $U_{I}(\hat{h})=U_{I I}(\hat{h})$. Recall that under any type of these equilibria, the type- $I$ workers are never worse off, and it is always the type- $I I$ workers whose allocations are distorted. Hence this ranking of types of equilibrium actually reflects the gradual enhancement of the welfare of the type- $I I$ workers. And since any improvement of the type- $I I$ workers' utility will lead to an increase in the marginal type$I$ workers' utility, this increment in utility is then translated to an increase in the threshold home production level, given that the envelope condition implies $\frac{\partial U_{I}}{\partial h}>0$.

The originality compared to Section 2 is this extensive margin on retirement. With pooling allocations, the distortions borne by the workers who work longer are lower than in the separating equilibrium. Indeed, in the separating equilibrium, the screening costs are borne by the workers who have a higher participation rate at the end of the life cycle. Without the screening process, the participation rate increases because the composition of the population is close to a homogenous group, i.e., we will arrive at the case of full information where two types of worker are separable. This result shows that when the dispersion of the outside options of the older workers is small, information could be regarded as precise, hence firms have no advantage in segmenting the labor market. Within a group with the same abilities at work (skills/diplomas), the heterogeneity of SS wealth and financial wealth can be small: thus, the pooling allocation will be the best strategy. Nevertheless, for the low-skilled workers, we also observed a large dispersion of the health state, which makes information in some sense imprecise. With respect to this last characteristic, the separating equilibrium thus has more probability of occurring. 


\subsection{Ex post heterogeneity and credible commitment}

In the previous sections, heterogeneity is perfectly observed at the first stage of the game: when searching for a job, workers already possess information on their probability of retirement or their expected home production level at the retirement age. This assumption is doubtless too strong, since we have implicitly ignored the uncertainties that one may encounter during the life cycle. Indeed, the main explaining factors for retirement choices (the SS wealth, financial wealth and health) can be viewed as random variables whose realization is unknown at the time when a labor contract is signed. In this section, we aim to capture this possibility in a two-period economy within a context similar to the ones employed previously.

From the theoretical point of view, the economy we are going to study differs from the previous ones in the following respects. With ex ante heterogeneity and asymmetric information, the employers' problem is to screen the undesirable types and to induce selfselection among the pool of workers. On the other hand, if the heterogeneity is observed by the worker (asymmetric information) only after the employment relationship has been established (ex post), the problem becomes one related to commitment: the employer's problem is to propose contracts allowing her to retain workers: she wants to make sure that the posted wage contract becomes a credible commitment if it is accepted, according to what is agreed at the ex-ante stage. In other words, the contract should ensure that ex post the workers do not break the contract unilaterally. Specifically, we are in a situation where firms have full commitment, whereas workers have limited commitment.

Our economy is closely related to the Guerrieri's paper (2008). Within a competitive search framework, she formalized a mechanism design in an economy where workers hold private information on their idiosyncratic working disutility realized immediately after the match is formed. Apart from a difference in workers' preferences (unlike Guerrieri, we take into account risk aversion), a crucial difference between our two frameworks comes from the impact of workers' heterogeneity. In the Guerrieri economy, heterogeneity matters for the utility of the worker inside the firm, but the workers' outside option (the unemployment benefit level) is unaffected by the heterogeneity and is always homogenous. In contrast, in our economy the heterogeneity in home production level alters not only the workers' retirement decisions, but also introduces heterogeneity in the workers' outside option. We propose some straightforward modifications of the techniques developed in Guerrieri (2008) to solve our problem, and we obtain the following results: (i) under asymmetric information, the workers choose to retire at an early stage, i.e. $\hat{h}^{A I}<\hat{h}^{F I}$ (qualitatively, this result is the same as the one obtained in the previous section), (ii) there is inferior job creation compared to the full information economy as in Guerrieri (2008).

In the setup, we will only mention the different elements compared to the previous contexts. Workers and firms are now ex ante identical. Once a match is formed, the worker receives a home production shock which takes place at the end of the 1st period during this employment relationship. Then depending on the realization of the home production level, the worker decides to work for another period or to retire early (without paying any 
compensation to the firm). We assume that the level of home production shock $h$ is drawn randomly from a cumulative distribution function $G($.$) , within the interval H \equiv[\underline{h}, \bar{h}]$. This realization becomes a private information known to workers. Thus the firm's problem is to propose a wage contract that (i) guarantees participation (Individual rationality), and (ii) makes sure the workers reveal truthfully their home production realization (Incentive compatibility).

We start with the incentive constraint. Let's define a function $e_{i}(h) \in\{0,1\}$, where $i \in\{I, I I\}$, as the probability that the firm will retain this type- $i$ worker, and we use $V(h, \tilde{h})$ to denote the expected utility for a worker of type $h$, who makes a report of her type as $\tilde{h}$.

$$
V(h, \tilde{h})=e_{I I}(\tilde{h}) u\left(W_{2}(\tilde{h})\right)+\left(1-e_{I I}(\tilde{h})\right) u(h+z)
$$

where $W_{2}(\tilde{h})$ is the wage function posted for the type- $\tilde{h}$ worker. The incentive compatible constraint (IC), ie. the constraint ensuring that the worker has the incentive to truthfully reveal her type, is thus

$$
\begin{aligned}
& V(h, h) \geq V(h, \tilde{h}) \quad \text { for all } h, \tilde{h} \in H \\
\Leftrightarrow & e_{I I}(h) u\left(W_{2}(h)\right)+\left(1-e_{I I}(h)\right) u(h+z) \geq e_{I I}(\tilde{h}) u\left(W_{2}(\tilde{h})\right)+\left(1-e_{I I}(\tilde{h})\right) u(h+z) \\
\Leftrightarrow & e_{I I}(h)\left[u\left(W_{2}(h)\right)-u(h+z)\right] \geq e_{I I}(\tilde{h})\left[u\left(W_{2}(\tilde{h})\right)-u(h+z)\right] \\
\Rightarrow & J(h, h) \geq J(h, \tilde{h})
\end{aligned}
$$

where $J(h, \tilde{h})$ is simply defined by

$$
J(h, \tilde{h})=e_{I I}(\tilde{h}) u\left(W_{2}(\tilde{h})\right)-e_{I I}(\tilde{h}) u(h+z)
$$

We now move to the individual rationality constraint, which guarantees that the workers participate voluntarily in the employment relationship after $h$ has been observed:

$$
V(h, h) \geq u(z+h) \Leftrightarrow J(h, h)+u(z+h) \geq u(z+h)
$$

Finally, we have two constraints to deal with:

1. IC constraint: $J(h, \tilde{h}) \leq J(h, h), \forall h, \tilde{h} \in H$.

2. IR constraint: $J(h, h)+u(h+z) \geq u(h+z)$ for all $h$; i.e. all the types would like to participate.

Lemma 1. The IC and IR constraints are equivalent to the following constraints:

(i) $I C^{\prime}: J(h, h)=J(\bar{h}, \bar{h})+\int_{h}^{\bar{h}} e_{I I}(\tau) u^{\prime}(\tau+z) d \tau$.

(ii) IR': the type with highest possibility of quitting would like to participate

$$
J(\bar{h}, \bar{h}) \geq 0 \rightarrow \int_{\underline{h}}^{\bar{h}} e_{I I}(h)\left[u\left(w_{I I, 2}\right)-u(h+z)-\frac{G(h)}{g(h)} u^{\prime}(h+z)\right] d G(h) \geq 0
$$


Proof. See Appendix J.

Given Lemma 1, and the fact the constraint IC' is included in the constraint IR', the dynamic programs are then the following:

$$
\begin{aligned}
U^{I C}= & \max _{\mathcal{C}_{I I}}\left\{\begin{array}{l}
F\left(q_{I I}\right)\left\{u\left(w_{I I, 1}\right)+\beta \int_{\underline{h}}^{\bar{h}}\left[e_{I I}(h) u\left(w_{I I, 2}\right)+\left(1-e_{I I}(h)\right) u(h+z)\right] d G(h)\right\} \\
+\left(1-F\left(q_{I I}\right)\right)\left\{u(z)+\beta \int_{\underline{h}}^{\bar{h}}\left[U_{I}(h+z)\right] d G(h)\right\}
\end{array}\right\} \\
\text { s.t. } \quad & F\left(q_{I I}\right) \int_{\underline{h}}^{\bar{h}}\left[y-w_{I I, 1}+\beta e_{I I}(h)\left(y-w_{I I, 2}\right)\right] d G(h) \geq \frac{C}{q_{I I}} \\
& \int_{\underline{h}}^{\bar{h}} e_{I I}(h)\left[u\left(w_{I I, 2}\right)-u(h+z)-\frac{G(h)}{g(h)} u^{\prime}(h+z)\right] d G(h) \geq 0
\end{aligned}
$$

with $\mathcal{C}_{I I}=\left\{e_{I I}(h), q_{I I}, w_{I I, 1}, w_{I I, 2}\right\}$, and the notation $U_{I}(h+z)$, which represents the expected utility for workers who did not find a job in the first period, is defined as follows:

$$
U_{I}(h+z)=\max \{U(z), u(h+z)\}=\max _{e_{I}}\left\{e_{I}(h) U(z)+\left(1-e_{I}(h)\right) u(h+z)\right\}
$$

There is no integral here, because the worker's type is already revealed at this stage. Moreover, we have

$$
\begin{aligned}
U(z)= & \max _{q_{I}, w_{I}}\left\{F\left(q_{I}\right) u\left(w_{I}\right)+\left(1-F\left(q_{I}\right)\right) u(z)\right\} \\
\text { s.t. } & H\left(q_{I}\right)\left(y-w_{I}\right) \geq C
\end{aligned}
$$

Notice that we require, for the workers who did not get employed in the first period, that whether they decide to participate or not in the second period, they compare $u(h+z)$ and $U(z)$. We deduce that the wage from a single period contract is identical for each period. Thus it is immediate that $u(z)<U(z)<u(w)$.

The FOC of the dynamic problem, with respect to $w_{I I, 1}$ and $w_{I I, 2}$ are:

$$
\begin{aligned}
& u^{\prime}\left(w_{I I, 1}\right)=\lambda \\
& u^{\prime}\left(w_{I I, 2}\right)=\lambda \frac{1}{1+\delta}
\end{aligned}
$$

The FOC are with respect to $q_{I I}$ implies

$$
\begin{array}{r}
{\left[u\left(w_{I I, 1}\right)-u(z)\right]} \\
+(1+\delta) \beta\left[\int_{\underline{h}}^{\bar{h}}\left[e_{I I}(h) u\left(w_{I I, 2}\right)+\left(1-e_{I I}(h)\right) u(h+z)\right] d G(h)-\int_{\underline{h}}^{\bar{h}} U_{I}(h+z) d G(h)\right] \\
+\lambda\left[\int_{\underline{h}}^{\bar{h}}\left[y-w_{I I, 1}+\beta e_{I I}(h)\left(y-w_{I I, 2}\right)\right] d G(h)+\frac{1}{F^{\prime}\left(q_{I I}\right) q_{I I}^{2}} C\right] \\
+\delta \beta\left[\int_{\underline{h}}^{\bar{h}} U_{I}(h+z) d G(h)+\int_{\underline{h}}^{\bar{h}}\left\{\left(1-e_{I I}(h)\right) u^{\prime}(h+z) \frac{G(h)}{g(h)}\right\} d G(h)-u(\bar{h}+z)\right]=0
\end{array}
$$


Finally, we shall do the pointwise maximization for $e(h)$ to find the optimal decision for retaining workers. Notice that from standard mechanism design theory, the incentive compatibility constraints imply that $e(h)$ should be a monotone function of $h$. As in Guerreri (2008), it could be checked that the first order condition implies a cutoff value $\hat{h}$ such that

$$
e(h)= \begin{cases}0 & \text { if } h \geq \hat{h} \\ 1 & \text { if } h<\hat{h}\end{cases}
$$

And the corresponding first order condition could be written as:

$$
\left[u\left(w_{I I, 2}\right)-u(\hat{h}+z)\right]+u^{\prime}\left(w_{I I, 2}\right)\left(y-w_{I I, 2}\right)-\frac{\delta}{1+\delta} u^{\prime}(\hat{h}+z) \frac{G(\hat{h})}{g(\hat{h})}=0
$$

Now we are interested in the comparison between the allocation of the full information and asymmetric information economy. We have the following proposition for the allocations in full the information economy:

Proposition 12. In the case of full information, ie. when $\delta=0$, we have $y=w_{1}=w_{2}=$ $\hat{h}^{F I}+z$ and $q^{F I}$ given by

$$
\frac{u(y)-u(z)}{u^{\prime}(y)}+\beta \frac{\left[G(\hat{h}) u(y)+\int_{\hat{h}}^{\bar{h}} u(h+z) d G(h)-\int_{\underline{h}}^{\bar{h}}\left[U_{I}(h+z)\right] d G(h)\right]}{u^{\prime}(y)}+\frac{1}{1-\epsilon_{H}\left(q^{F I}\right)} \frac{C}{H\left(q^{F I}\right)}=0
$$

Proof. In the full information case, the incentive constraint does not matter. Thus $\delta=0$. Straightforward by using the FOC with $\delta=0$.

In case of full information (with no commitment problem), we have $y=w_{2}=\hat{h}^{F I}+z$. This comes from the following two restrictions: a) it is necessary that $y-w_{2} \geq 0$ otherwise $y-w_{1}=y-w_{2}<0$ will imply a negative surplus for firms; b) it has to be true that $u\left(w_{2}\right) \geq u(\hat{h}+z)$, otherwise $w_{2}<\hat{h}+z$ will imply that workers choose to stay at work while retirement is a better option. As in Guerrieri (2008), the first-best level of job creation is reached when the wages are equal to the firm's productivity, which implies that firms earn zero profits. Notice that this is inconsistent with an equilibrium where firms pay a positive vacancy cost. Thus, in the full information case, the workers get all the productivity but must pay for the vacancy $\operatorname{costs}^{19}$. Finally, note that this queue length does not share the same characteristics as in the case where the separation is exogenous (see Section 2.1.1).

${ }^{19}$ One can derive $q^{F I}$ from the following program:

$$
\begin{aligned}
U^{F I}= & \max _{q} F(q)\left\{u(y)+\beta \int_{\underline{h}}^{y-z}[u(y)-u(h+z)] d G(h)+\beta \int_{\underline{h}}^{\bar{h}}[u(h+z)] d G(h)\right\} \\
& +(1-F(q))\left\{u(z)+\beta \int_{\underline{h}}^{\bar{h}} U_{I}^{I C}(h+z) d G(h)\right\}-\frac{1}{q} u^{\prime}(y) C
\end{aligned}
$$


Indeed, the endogeneity of the retirement age allows workers to push up the wages. On the other hand, when the retirement age is exogenous, the absence of a participation constraint allows firms to conserve positive profits, and thus a positive weight in the optimal sharing rule $\left(\epsilon_{H}(q)\right)$. Now we are ready for the comparison:

Proposition 13. In the asymmetric information case, ie. when $\delta>0$, we have

- $w_{I I, 1}<w_{I I, 2}<y$,

- $\hat{h}^{I C}<\hat{h}^{F I}$ and

- $q_{I I}>q^{F I}$

Given that $q^{F I}<q_{I I}$ implies $F\left(q^{F I}\right)>F\left(q_{I I}\right)$, and since $G\left(\hat{h}^{F I}\right)>G\left(\hat{h}^{I C}\right)$, we are able to conclude that $F\left(q^{F I}\right) G\left(\hat{h}^{F I}\right)>F\left(q_{I I}\right) G\left(\hat{h}_{I I}\right)$ : the job matching is inferior in the asymmetric information case.

Proof. See Appendix N

This proposition shows that an increasing wage profile is induced in order to achieve commitment, contrary to the case with full information where the wages are constant. Given that the reservation threshold of the leisure value is lower in the economy with asymmetric information, the individuals choose then to retire sooner than in an economy with full information. Thus, imperfect information leads to under-employment. We have established that the ex ante and ex post heterogeneity both lead to the same results concerning this extensive margin. But the causes are not the same. Indeed, in the ex post heterogeneity case, workers do not know ex ante if they will work 1 or 2 periods, but ex post, they obtain this information and have the choice to retire or not (they do not have to commit). At the time of investment in vacancies, firms and workers share the same information. This is not the case when the heterogeneity is known by the worker ex ante, where firms must introduce a screening process in order to avoid hiring workers who know that they will work only one period. In the case of the ex post heterogeneity, the problem of the firm becomes the lack of commitment of the worker who has signed a long term contract: at the end of the life cycle, the firm must find how to hold the workers, even if their new information gives them incentives to retire. This power to quit the job without any cost leads firms to give all the productivity to the marginal worker, in the full information case. In the asymmetric information case, the rise in the wage allows firms to retain some workers. Nevertheless, the last wage is lower than the marginal productivity in order to prevent the worker from reporting that she is the marginal worker, asking in this case a too high wage (at the limit, the productivity).

Moreover, the queue length is longer in the economy with imperfect information: the efficiency of the matching process is thus lower. Hence, the under-employment linked to the individual decisions of retirement is magnified by the less efficient matching process. 


\section{Conclusion}

In this paper, we deal with an adverse-selection problem within a competitive search environment, where the horizon of the worker is not perfectly observable for firms: one group is composed of workers who retire soon, and the second consists of workers who have high value in the job and would like to stay longer. Firms sink investment in vacancies ex ante and post contracts in the hope of attracting the right workers to recoup invest costs. Thus, we are concerned with the relationship between the expected duration of the employment relationship, the wages and the hiring decisions.

We first show that the long term employment relationship is preferred by the workers when information is complete. When workers are risk-averse, the wages are constant over the life cycle. We then deduce that if the information is asymmetrical in favor of the employees, the 'bad' workers can have an incentive to cheat, by applying for a long term contract and quitting before the end of the contract (there is no commitment). Nevertheless, in a basic model where the retirement decision is exogenous, we show that firms implement a screening process: the optimal separating contract distorts the allocation of the 'good' workers in order to prevent the 'bad' workers from applying for these jobs. This contract is characterized by wage dynamics which are age-increasing. This separating equilibrium always exists, but when the fraction of bad types is low, a pooling allocation can be constructed to make both types of worker better off, so that the separating equilibrium is Pareto dominated. From a theoretical point of view, these results are close to the ones discussed in Guerrieri, Shimer and Wright (2010), except that we do not deal with the intensive margin. With respect to the labor market of the older workers, our results give an alternative foundation to the rise of the wage with the worker's age. Indeed, in Lazear (1979), firms must deal with the problem with unobservability of the effort at work. Thus, an age-increasing wage profile solves a moral hazard problem. Nevertheless, our solution is closest to the one discussed by Salop and Salop (1976), who consider a Two-Part Wage mechanism to induce a self-selection. This Two-Part Wage device requires that a new employee pays the firm an entrance fee, in return for which she will receive in the subsequent periods a higher wage (the wages increase with the tenure of the workers). In the equilibrium, the workers should pay for their own turnover costs. This is equivalent to saying that this worker pays a deposit which is a guarantee corresponding to the consequences of the lack of commitment. We generalize this result in a context of an equilibrium search model and we show that this contract ensures the existence of a separating equilibrium.

In the second part, we endogenize the retirement decision. The interest of these extensions is to deal with the problem of the sub-optimality of the employment rate of the older workers. We have considered two cases: an ex ante or an ex post heterogeneity. As in the case where retirement is exogenous, both types of heterogeneity lead firms to post contracts allowing them to implement a screening process which leads to separating between the bad and the good type workers: in the long-term contract, the wage increases with the worker's age, reducing the welfare of the 'good' worker. When the workers know at the beginning of their careers the outside options they will get at the end of their life cycle, the employment rate 
of the older workers is lower than in an economy where the information is complete because distorted wage contracts reduce their labor supply. These results clearly suggest that the less transparent the SS system, the lower will be the employment rate of the older workers. Finally, in the case of an ex-post heterogeneity (e.g. in the case of an unexpected health or wealth shocks during the career), we show that if the shock is private information for the workers at the end of their life cycle, firms have less incentive to hire workers on longterm contracts, reenforcing the low employment rate of the older worker. Thus, it seems that under-employment of the older worker linked to the asymmetry in the information is a robust result, even if contracts can support a separating equilibrium in a competitive search environment.

\section{References}

[1] Kenneth Burdett \& Shouyong Shi \& Randall Wright, 2001. "Pricing and Matching with Frictions", Journal of Political Economy, vol. 109(5), pages 1060-1085, October.

[2] Melanie Cao \& Shouyong Shi, 2000. "Coordination, matching, and wages", Canadian Journal of Economics, vol. 33(4), pages 1009-1033, November.

[3] Arnaud Cheron \& Jean-Olivier Hairault \& François Langot, 2011. "Age-Dependent Employment Protection", Economic Journal, vol. 121, pages 1477-1504.

[4] Arnaud Cheron \& Jean-Olivier Hairault \& François Langot, 2013. "Life-Cycle Equilibrium Unemployment", Journal of Labor Economics, vol. 31 (4), pages 843-882, October.

[5] David Cutler \& Ellen Meara \& Seth Richards-Shubik, 2011. "Healthy Life Expectency: Estimates and Implications for Retirement Age Policy ", NBER Retirement Research Center Paper, NB 10-11, November.

[6] Manolis Galenianos \& Philipp Kircher, 2012. "On The Game-Theoretic Foundations Of Competitive Search Equilibrium", International Economic Review, vol. 53(1), pages $1-21,02$.

[7] Jonathan Gruber \& David Wise, 1999. "Social Security and Retirement around the World", NBER Chapters, in: Social Security and Retirement around the World, pages 1-35 National Bureau of Economic Research, Inc.

[8] Veronica Guerrieri \& Robert Shimer \& Randall Wright, 2010. "Adverse Selection in Competitive Search Equilibrium", Econometrica, vol. 78(6), pages 1823-1862, November.

[9] Veronica Guerrieri, 2008. "Inefficient Unemployment Dynamics under Asymmetric Information", Journal of Political Economy, vol. 116(4), pages 667-708, 08. 
[10] Jean-Olivier Hairault \& Francois Langot \& Thepthida Sopraseuth, 2010. "Distance to Retirement and Older Workers' Employment: The Case for Delaying the Retirement Age", Journal of the European Economic Association, vol. 8(5), pages 1034-1076, 09.

[11] Jean-Olivier Hairault \& François Langot \& Andre Zylberberg, 2012. "Equilibrium Unemployment and Retirement", IZA Discussion Papers 6511, Institute for the Study of Labor (IZA).

[12] Edward Lazear, 1979. "Why is there mandatory retirement?" Journal of Political Economy, vol. 87(6), pages 1261-1284.

[13] Guido Menzio \& Irina Telyukova \& Ludo Visschers, 2012. "Directed Search over the Life Cycle", PIER Working Paper Archive 12-002, Penn Institute for Economic Research, Department of Economics, University of Pennsylvania.

[14] Espen Moen, 1997. "Competitive search equilibrium", Journal of Political Economy, vol. 105(2), pages 386-411.

[15] Dale Mortensen, 2011. "Autobiography", Nobel Prize in Economics documents 2010-5, Nobel Prize Committee.

[16] David Neumark, 2001, "Age discrimination legislation in the United States", NBER working paper, 8152 .

[17] Edmund Phelps, 1970, "Microeconomic Foundations of Employment and Inflation Theory", W.W. Norton \& Company

[18] Michael Rothschild \& Joseph Stiglitz, 1976. "Equilibrium in Competitive Insurance Markets: An Essay on the Economics of Imperfect Information,", The Quarterly Journal of Economics, vol. 90(4), pages 629-649, November.

[19] Joanne Salop and Steven Salop. "Self-Selection and Turnover in the Labor Market", Quarterly Journal of Economics, vol. 90(4), 619-627, November.

[20] Shouyong Shi, 2006. "Wage differentials, discrimination and efficiency", European Economic Review, vol. 50(4), pages 849-875, May.

[21] Shouyong Shi, 2002. "A Directed Search Model of Inequality with Heterogeneous Skills and Skill-Based Technology", Review of Economic Studies, vol. 69(2), pages 467-91, April.

[22] Shouyong Shi, 2002. "Product Market and the Size-Wage Differential", International Economic Review, vol. 43(1), pages 21-54, February. 


\section{A Proof of the Proposition 1}

The proof of Proposition 1 could be easily established by comparing the solutions of the following programs where we take $p=1$ and $p=0$ respectively:

$$
\begin{array}{ll}
U_{I I}= & \max _{q} F(q)\left[u\left(w_{1}\right)+\beta u\left(w_{2}\right)\right]+(1-F(q))\left(u(z)+\beta U_{I}\right) \\
\text { s.to } & H(q)\left[(1+\beta) y-w_{1}-\beta w_{2}\right] \geq C
\end{array}
$$

where,

$$
\begin{aligned}
U_{I}= & \max _{q} F(q) u(w)+(1-F(q)) u(z) \\
\text { s.to } & H(q)[y-w] \geq C
\end{aligned}
$$

The solution for type $I I$ workers is determined by the following two equations (with $\beta=0$, the following system gives the solution for type $I$ workers $)^{20}$ :

$$
\begin{aligned}
\frac{1-\epsilon_{H}\left(q_{I I}\right)}{\epsilon_{H}\left(q_{I I}\right)} & =\frac{y-w_{I I}}{\frac{1}{u^{\prime}\left(w_{I I}\right)} \times\left[u\left(w_{I I}\right)-\frac{1}{(1+\beta)}\left(\beta U_{I}+u(z)\right)\right]} \\
H\left(q_{I I}\right)(1+\beta)\left[y-w_{I I}\right] & =C
\end{aligned}
$$

Result 1: $w_{I I}>w_{I}$. Since the type- $I I$ 's problem coincides with the type- $I$ 's problem with $\beta=0$, it is sufficient to verify whether $\frac{d w_{I I}}{d \beta}>0$.

We thus consider the implicit function defined by rearranging the first order condition:

$$
I\left(w_{I I}, \beta\right)=u\left(w_{I I}\right)-\frac{1}{(1+\beta)}\left(\beta U_{I}+u(z)\right)-u^{\prime}\left(w_{I I}\right)\left(y-w_{I I}\right) \frac{\epsilon_{H}\left(q_{I I}\left(w_{I I}\right)\right)}{1-\epsilon_{H}\left(q_{I I}\left(w_{I I}\right)\right)}=0
$$

where $q_{I I}\left(w_{I I}\right)$ is defined by the Free-entry condition. have

We want to show $\frac{d w_{I I}}{d \beta}=-\frac{I_{\beta}}{I_{w_{I I}}}>0$, where $I_{\beta}=\frac{d I}{d \beta}$ and $I_{w_{I I}}=\frac{d I}{d w_{I I}}$. Given $I\left(w_{I I}, \beta\right)$, we

$$
\begin{aligned}
I_{\beta}= & \underbrace{-\frac{1}{(1+\beta)^{2}} U_{I}+\frac{1}{(1+\beta)^{2}} u(z)}_{<0} \\
& \underbrace{-u^{\prime}\left(w_{I I}\right)\left\{y-w_{I I}\right\} \times \frac{1}{\left(1-\epsilon_{H}\right)^{2}} \epsilon_{H}^{\prime} \frac{1}{H^{\prime}\left(q_{I I}\right)} \frac{-C}{(1+\beta)^{2}\left(y-w_{I I}\right)}}_{<0}<0
\end{aligned}
$$

On the other hand, $I\left(w_{I I}, \beta\right)$ leads to

$$
\begin{aligned}
I_{w_{I I}}= & \underbrace{u^{\prime}\left(w_{I I}\right)}_{>0} \underbrace{-u^{\prime \prime}\left(w_{y}\right)\left(y-w_{I I}\right)\left[\frac{1}{1-\epsilon_{H}}-1\right]}_{>0}+\underbrace{u^{\prime}\left(w_{I I}\right)\left[\frac{1}{1-\epsilon_{H}}-1\right]}_{>0} \\
& \underbrace{u^{\prime}\left(w_{I I}\right)\left(y-w_{I I}\right)\left(\frac{1}{1-\epsilon_{H}}\right)^{2} \overbrace{\epsilon_{H}^{\prime}}^{<0} \frac{1}{H^{\prime}\left(q_{I I}\right)} \frac{C}{1+\beta}\left(\frac{1}{y-w_{I I}}\right)^{2}>0}_{<0}
\end{aligned}
$$

\footnotetext{
${ }^{20}$ The elasticity for the workers' job finding rate and the elasticity for the firms' hiring probability admit the following relationship: $\epsilon_{F}\left(q_{I I}\right)=\epsilon_{H}\left(q_{I I}\right)-1$.
} 
Thus in total $\frac{d w_{I I}}{d \beta}>0$, leading to $w_{I I}>w_{I}$.

Result 2: $q_{I I}<q_{I}$. The simplest way is to use the same argument as above and to prove $\frac{d q_{I I}}{d \beta}<0$. We thus consider the implicit function defined and obtained by rearranging the first order condition:

$$
\begin{aligned}
X\left(q_{I I}, \beta\right) & =0 \\
& =u\left(w_{I I}\left(q_{I I}\right)\right)-\frac{1}{(1+\beta)}\left(\beta U_{I}+u(z)\right)-u^{\prime}\left(w_{I I}\left(q_{I I}\right)\right)\left(y-w_{I I}\left(q_{I I}\right)\right) \frac{\epsilon_{H}\left(q_{I I}\right)}{1-\epsilon_{H}\left(q_{I I}\right)}
\end{aligned}
$$

where $w_{I I}\left(q_{I I}\right)$ is defined and obtained by the Free-entry condition. Implicit function theorem leads to $\frac{d q_{I I}}{d \beta}=-\frac{X_{\beta}}{X_{q_{I I}}}$, where $X_{q_{I I}}=\frac{d X}{d q_{I I}}$ and $X_{\beta}=\frac{d X}{d \beta}$. These derivatives are given by:

$$
\begin{aligned}
& X_{q_{I I}}=\underbrace{u^{\prime}\left(w_{I I}\right) \overbrace{\left.\frac{d w_{I I}}{d q_{I I}}\right|_{F O C}}^{>0}-\left.u^{\prime \prime}\left(w_{y}\right)\left(y-w_{I I}\right)\left[\frac{1}{1-\epsilon_{H}\left(q_{I I}\right)}-1\right] \frac{d w_{I I}}{d q_{I I}}\right|_{F O C}}_{>0} \\
& +\underbrace{\left.u^{\prime}\left(w_{I I}\right)\left[\frac{1}{1-\epsilon_{H}\left(q_{I I}\right)}-1\right] \frac{d w_{I I}}{d q_{I I}}\right|_{F O C}-u^{\prime}\left(w_{I I}\right)\left(y-w_{I I}\right)\left(\frac{1}{1-\epsilon_{H}}\right)^{2} \overbrace{\epsilon_{\epsilon_{H}^{\prime}}^{<0}}^{\underbrace{\prime}}}_{>0} \\
& X_{\beta}=\underbrace{\overbrace{u^{\prime}\left(w_{I I}\right) \frac{C}{H\left(q_{I I}\right)}\left(\frac{1}{1+\beta}\right)^{2}}^{\lessgtr}-\frac{1}{(1+\beta)^{2}} U_{I}+\frac{1}{(1+\beta)^{2}} u(z)}_{>0} \\
& \underbrace{-\frac{\epsilon_{H}\left(q_{I I}\right)}{1-\epsilon_{H}\left(q_{I I}\right)} \frac{C}{H\left(q_{I I}\right)}\left(\frac{1}{1+\beta}\right)^{2}\left[u^{\prime \prime}\left(y-w_{I I}\right)-u^{\prime}\right]}_{>0}
\end{aligned}
$$

There seems to be ambiguity for the sign of $X_{\beta}$. We now try to rearrange it in this way:

$$
\begin{aligned}
X_{\beta} & =\frac{1}{(1+\beta)^{2}}\left\{u^{\prime}\left(w_{I I}\right) \frac{C}{H\left(q_{I I}\right)}-U_{I}+u(z)-\frac{\epsilon_{H}\left(q_{I I}\right)}{1-\epsilon_{H}\left(q_{I I}\right)} \frac{C}{H\left(q_{I I}\right)}\left[u^{\prime \prime}\left(y-w_{I I}\right)-u^{\prime}\right]\right\} \\
& =\frac{1}{(1+\beta)^{2}}\left\{u^{\prime}\left(w_{I I}\right) \frac{C}{H\left(q_{I I}\right)}-U_{I}+u(z) \frac{\epsilon_{H}\left(q_{I I}\right)}{1-\epsilon_{H}\left(q_{I I}\right)} \frac{C}{H\left(q_{I I}\right)} u^{\prime \prime}\left(y-w_{I I}\right)+\frac{\epsilon_{H}\left(q_{I I}\right)}{1-\epsilon_{H}\left(q_{I I}\right)} \frac{C}{H\left(q_{I I}\right)} u^{\prime}\right\}
\end{aligned}
$$

we combine terms containing $u$ to obtain:

$$
X_{\beta}=\frac{1}{(1+\beta)^{2}}\left\{\frac{1}{1-\epsilon_{H}\left(q_{I I}\right)} u^{\prime}\left(w_{I I}\right) \frac{C}{H\left(q_{I I}\right)}-U_{I}+u(z)-\frac{\epsilon_{H}\left(q_{I I}\right)}{1-\epsilon_{H}\left(q_{I I}\right)} \frac{C}{H\left(q_{I I}\right)} u^{\prime \prime}\left(y-w_{I I}\right)\right\}
$$

We use first order condition to rewrite

$$
\begin{aligned}
X_{\beta} & =\frac{1}{(1+\beta)^{2}}\left\{\frac{1}{\epsilon_{H}}\left[(1+\beta) u\left(w_{I I}\right)-\beta U_{I}-u(z)\right]-U_{I}+u(z)-\frac{\epsilon_{H}\left(q_{I I}\right)}{1-\epsilon_{H}\left(q_{I I}\right)} \frac{C}{H\left(q_{I I}\right)} u^{\prime \prime}\left(y-w_{I I}\right)\right\} \\
& =\frac{1}{(1+\beta)^{2}}\{\frac{1}{\epsilon_{H}} \beta\left[u\left(w_{I I}\right)-U_{I}\right]+\underbrace{\overbrace{\frac{1}{\epsilon_{H}}}^{>1}\left[u\left(w_{I I}\right)-u(z)\right]-\left[U_{I}-u(z)\right]-\frac{\epsilon_{H}\left(q_{I I}\right)}{1-\epsilon_{H}\left(q_{I I}\right)} \frac{C}{H\left(q_{I I}\right)} u^{\prime \prime}\left(y-w_{I I}\right)}_{>0}\}
\end{aligned}
$$


We deduce that $X_{\beta}>0$, and thus $\frac{d q_{I I}}{d \beta}=-\frac{X_{\beta}}{X_{q_{I I}}}<0$. This implies that the surplus of the firms is increasing in the value of $\beta$, leading to $q_{I I}<q_{I}$.

\section{B Proof of Proposition 2}

Proof. From Proposition 1, we have $w_{I I, 1}=w_{I I, 2}=w_{I I}>w_{I}=w_{I, 1}$, hence workers are better off in the ex post welfare. Now turn to the case concerning the ex ante welfare. Denote $U_{I I}$ the utility of a worker who can work for 2 periods, and $U_{I}$ the worker who is only willing to work for 1 period, where

$$
\begin{aligned}
U_{I I} & =F\left(q_{I I}\right)\left[u\left(w_{I I, 1}\right)+\beta u\left(w_{I I, 2}\right)\right]+\left(1-F\left(q_{I I}\right)\right)\left[u(z)+\beta U_{I}\right] \\
U_{I} & =F\left(q_{I}\right) u\left(w_{I, 1}\right)+\left(1-F\left(q_{I}\right)\right) u(z)
\end{aligned}
$$

$\left(q_{I I}, w_{I I, 1}, w_{I I, 2}\right)$ and $\left(q_{I}, w_{I}\right)$ represent the endogenous variables at optimal level.

We need to show that $U_{I I}>(1+\beta) U_{I}$. Reorganizing terms, we could establish the result in the following manner.

$$
\begin{aligned}
U_{I I} & =F\left(q_{I I}\right)\left[u\left(w_{I I, 1}\right)+\beta u\left(w_{I I, 2}\right)\right]+\left(1-F\left(q_{I I}\right)\right)\left[u(z)+\beta U_{I}\right] \\
& =\left\{F\left(q_{I I}\right)\left[u\left(w_{I I, 1}\right)-u(z)\right]+u(z)\right\}+\beta\left\{F\left(q_{I I}\right)\left[u\left(w_{I I, 2}\right)-U_{I}\right]+U_{I}\right\} \\
& >U_{I}+\beta\left\{F\left(q_{I I}\right)\left[u\left(w_{I I, 2}\right)-U_{I}\right]+U_{I}\right\} \\
& >U_{I}+\beta U_{I}
\end{aligned}
$$

The first inequality is induced by virtue of Proposition 1, along with the facts that $u($.$) is an$ increasing function and $F($.$) is a decreasing function. We hence have F\left(q_{I I}\right)\left[u\left(w_{I I, 1}\right)-u(z)\right]>$ $F\left(q_{I}\right)\left[u\left(w_{I, 1}\right)-u(z)\right]$, since each term on the left hand side is larger in value than the corresponding terms on the right hand side.

The second inequality is induced because of the following series of inequalities:

$$
\beta\left\{F\left(q_{I I}\right)\left[u\left(w_{I I, 2}\right)-U_{I}\right]+U_{I}\right\}>\beta\left\{F\left(q_{I}\right)\left[u\left(w_{I, 1}\right)-U_{I}\right]+U_{I}\right\}>\underbrace{\beta\left\{F\left(q_{I}\right)\left[u\left(w_{I, 1}\right)-u(z)\right]+u(z)\right\}}_{=U_{I}}
$$

The first inequality of the above chain is owing to Proposition 1. And the second inequality of the above chain is obtained due to the fact that the equilibrium value $U_{I}^{x}$, which is defined by the solution of the following program $U_{I}^{x}=\max \{F(q)[u(w)-x]+x\}$, s.to $H(q)(y-w) \geq C$, is increasing in $x$. The proposition is thus shown. We shall make the supplementary remark that the result $U_{I I}>(1+\beta) U_{I}$ implies that $\frac{\partial U_{I I}}{\partial \beta}>1$.

\section{Proof of Proposition 3}

A separating contract always exists. We will show that the equilibrium allocation satisfies the 3 main assumptions (emphasized by GSW), which are required for the existence and uniqueness of the competitive search equilibrium. 
A1) Monotonicity. Given any wage profile $\left(w_{1}, w_{2}\right)$, the ex post surplus of firms should be monotonic in $p$. This is satisfied, because $\left(y-w_{1}\right)+\beta p_{H}\left(y-w_{2}\right)>\left(y-w_{1}\right)+$ $\beta p_{L}\left(y-w_{2}\right)$

A2) Local non-satiation. Given any feasible wage profile $\left(w_{1}, w_{2}\right)$, there exists a wage profile $\left(\hat{w}_{1}, \hat{w}_{2}\right)$ which is close enough to $\left(w_{1}, w_{2}\right)$, i.e., in some $\epsilon$ neighborhood of $\left(w_{1}, w_{2}\right)$ such that

1) If for the firms, $\left(y-\hat{w}_{1}\right)+\beta p\left(y-\hat{w}_{2}\right)>\left(y-w_{1}\right)+\beta p\left(y-w_{2}\right)$, i.e., $\left(\hat{w}_{1}, \hat{w}_{2}\right)$ raises the principal's ex post surplus

2) then, for the workers, $u\left(\hat{w}_{1}\right)+\beta p u\left(\hat{w}_{2}\right)-u(z)+\beta p U_{I} \leq u\left(w_{1}\right)+\beta p u\left(w_{2}\right)-u(z)+$ $\beta p U_{I}$, i.e., $\left(\hat{w}_{1}, \hat{w}_{2}\right)$ lowers the agent's ex post surplus

This is possible: we consider sufficiently small adjustment $(h, k)$ with $\hat{w}_{1}=w_{1}+h$ and $\hat{w}_{2}=w_{2}+k$, such that 1) $\left.\sqrt{h^{2}+k^{2}}<\epsilon, 2\right)|h|<\beta p|k|$ and 3) $u^{\prime}\left(w_{1}\right) h+\beta p u^{\prime}\left(w_{2}\right) k<0$.

A3) Sorting (similar to single-crossing). Given any type $i$, and given any feasible wage profile $\left(w_{1, i}, w_{2, i}\right)$ for this type $i$, there exists a wage profile $\left(\hat{w}_{1}, \hat{w}_{2}\right)$ which is close enough to $\left(w_{1, i}, w_{2, i}\right)$, i.e., in some $\epsilon$ neighborhood of $\left(w_{1, i}, w_{2, i}\right)$ such that

1) for $j \geq i$ (types better than $i$ ):

$$
u\left(\hat{w}_{1}\right)+\beta p_{j} u\left(\hat{w}_{2}\right)-u(z)+\beta p_{j} U_{I} \geq u\left(w_{1, i}\right)+\beta p_{j} u\left(w_{2, i}\right)-u(z)+\beta p_{j} U_{I}
$$

2) for $j<i($ types worse than $i)$ :

$$
u\left(\hat{w}_{1}\right)+\beta p_{j} u\left(\hat{w}_{2}\right)-u(z)+\beta p_{j} U_{I}<u\left(w_{1, i}\right)+\beta p u\left(w_{2, i}\right)-u(z)+\beta p_{j} U_{I}
$$

Proof of A3): consider an intermediary type $p_{\alpha}=\alpha p_{H}+(1-\alpha) p_{L}$ and consider a deviation $\left(w_{1, \alpha}+h, w_{2, \alpha}+k\right)$. For a type $i$ worker, this deviating profile will change utility by approximately the following amounts:

$$
\begin{aligned}
& \left\{u\left(w_{1, \alpha}+h\right)+\beta p_{H} u\left(w_{2, \alpha}+k\right)-u(z)+\beta p_{H} U_{I}\right\}-\left\{u\left(w_{1, \alpha}\right)+\beta p_{H} u\left(w_{2, \alpha}\right)-u(z)+\beta p_{H} U_{I}\right\} \\
\approx & u^{\prime}\left(w_{1, \alpha}\right) h+\beta p_{H} u^{\prime}\left(w_{2, \alpha}\right) k \\
& \left\{u\left(w_{1, \alpha}+h\right)+\beta p_{L} u\left(w_{2, \alpha}+k\right)-u(z)+\beta p_{L} U_{I}\right\}-\left\{u\left(w_{1, \alpha}\right)+\beta p_{L} u\left(w_{2, \alpha}\right)-u(z)+\beta p_{L} U_{I}\right\} \\
\approx & u^{\prime}\left(w_{1, \alpha}\right) h+\beta p_{L} u^{\prime}\left(w_{2, \alpha}\right) k
\end{aligned}
$$

By continuity of linear functions and since $p_{L}<p_{H}$, we could always find a $(h, k)$ with, for example, $h<0$ and $k>0$, such that the increments satisfy

$$
\begin{gathered}
u^{\prime}\left(w_{1, \alpha}\right) h+\beta p_{L} u^{\prime}\left(w_{2, \alpha}\right) k<0<u^{\prime}\left(w_{1, \alpha}\right) h+\beta p_{H} u^{\prime}\left(w_{2, \alpha}\right) k \\
\frac{\beta p_{L} u^{\prime}\left(w_{2, \alpha}\right)}{u^{\prime}\left(w_{1, \alpha}\right)}<-\frac{h}{k}<\frac{\beta p_{H} u^{\prime}\left(w_{2, \alpha}\right)}{u^{\prime}\left(w_{1, \alpha}\right)}
\end{gathered}
$$

and if we require $h=-\gamma k$, then $\sqrt{\left(w_{1, \alpha}+h-w_{1, \alpha}\right)^{2}+\left(w_{2, \alpha}+k-w_{2, \alpha}\right)^{2}}$ can be make smaller than $\epsilon$, as long as $k<\frac{\epsilon}{\sqrt{1+\gamma^{2}}}$. 


\section{Proof of Proposition 4}

Claim 1: $w_{1, H}^{A I}<w_{2, H}^{A I}$. Consider the lagragian of the program:

$$
\begin{aligned}
L= & F(q)\left[u\left(w_{1}\right)+\beta p_{H} u\left(w_{2}\right)\right]+(1-F(q))\left(u(z)+\beta p_{H} U_{I}\right) \\
& +\lambda\left\{H(q)\left[y-w_{1}+\beta p_{H}\left(y-w_{2}\right)\right]-C\right\} \\
& -\delta\left\{F(q)\left[u\left(w_{1}\right)+\beta p_{L} u\left(w_{2}\right)\right]+(1-F(q))\left(u(z)+\beta p_{L} U_{I}\right)-U_{L}\right\}
\end{aligned}
$$

Solving the FOCs, with respect to $w_{1}, w_{2}$ and $q$ :

$$
\begin{aligned}
F(q) u^{\prime}\left(w_{1}\right)-\lambda H(q)-\delta F(q) u^{\prime}\left(w_{1}\right) & =0 \\
F(q) \beta p_{H} u^{\prime}\left(w_{2}\right)-\lambda \beta p_{H} H(q)-\delta F(q) \beta p_{L} u^{\prime}\left(w_{2}\right) & =0 \\
F^{\prime}(q)\left[u\left(w_{1}\right)+\beta p_{H} u\left(w_{2}\right)-u(z)-\beta p_{H} U_{I}\right] & \\
+\lambda H^{\prime}(q)\left[y-w_{1}+\beta p_{H}\left(y-w_{2}\right)\right]-\delta F^{\prime}(q)\left\{\left[u\left(w_{1}\right)+\beta p_{L} u\left(w_{2}\right)\right]-\left(u(z)+\beta p_{L} U_{I}\right)\right\} & =0
\end{aligned}
$$

We can rearrange the two first FOC to obtain the following equations:

$$
\begin{aligned}
u^{\prime}\left(w_{1, H}^{A I}\right) & =\frac{\lambda q}{1-\delta} \\
u^{\prime}\left(w_{2, H}^{A I}\right) & =\frac{\lambda q}{1-\delta \frac{p_{L}}{p_{H}}}<\frac{\lambda q}{1-\delta}=u^{\prime}\left(w_{1, H}^{A I}\right)
\end{aligned}
$$

We deduce that (i) $w_{1, H}^{A I}<w_{2, H}^{A I}$ and (ii) $0<\delta<1$.

Claim 2a: $w_{1, H}^{A I}<w_{L}$. Suppose $w_{1, H}^{A I} \geq w_{L}$. Because we already established $w_{1, H}^{A I}<$ $w_{2, H}^{A I}$, then from the binding IC constraint

$$
\begin{aligned}
& F\left(q_{H}^{A I}\right)\left[u\left(w_{1, H}^{A I}\right)+\beta p_{L} u\left(w_{2, H}^{A I}\right)\right]+\left(1-F\left(q_{H}^{A I}\right)\right)\left(u(z)+\beta p_{L} U_{I}\right) \\
= & F\left(q_{L}\right)\left[u\left(w_{1, L}\right)+\beta p_{L} u\left(w_{2, L}\right)\right]+\left(1-F\left(q_{L}\right)\right)\left(u(z)+\beta p_{L} U_{I}\right) \\
= & U_{L}
\end{aligned}
$$

We could conclude that $F\left(q_{H}^{A I}\right) \leq F\left(q_{L}\right)$. Thus $q_{H}^{A I} \geq q_{L}$.

The FOC with respect to $q$ for type $H$ could be rewritten in the following way:

$$
\begin{aligned}
& \frac{1}{1-\delta} \frac{1}{u^{\prime}\left(w_{1, H}^{I C}\right)}\left\{\left[u\left(w_{1}\right)+\beta p_{H} u\left(w_{2}\right)-u(z)-\beta p_{H} U_{I}\right]-\delta\left[u\left(w_{1}\right)+\beta p_{L} u\left(w_{2}\right)-u(z)-\beta p_{L} U_{I}\right]\right\} \\
= & -\frac{H^{\prime}(q)}{F^{\prime}(q)} \frac{1}{q} \frac{C}{H(q)}
\end{aligned}
$$

The FOC with respect to $q$ for type $L$ could be rewritten in the following way:

$$
\frac{1}{u^{\prime}\left(w_{L}\right)}\left[u\left(w_{L}\right)+\beta p_{L} u\left(w_{L}\right)-u(z)-\beta p_{L} U_{I}\right]=-\frac{H^{\prime}(q)}{F^{\prime}(q)} \frac{1}{q} \frac{C}{H(q)}
$$

First, we notice that, the RHS of both FOC is strictly decreasing in $q$. Because we can make use of the relationship $H(q)=F(q) q$ to rewrite it as

$$
-\frac{H^{\prime}(q)}{F^{\prime}(q)} \frac{1}{q} \frac{C}{H(q)}=-\frac{H^{\prime}(q)}{\frac{H^{\prime}(q)}{q}-\frac{H(q)}{q^{2}}} \frac{1}{q} \frac{C}{H(q)}=\underbrace{\frac{\epsilon_{H}}{1-\epsilon_{H}}}_{\text {decreasing in } q_{H}} \frac{C}{H(q)}
$$


Secondly, it could be noticed that if we substitute $w_{L}$ on the LHS of the FOC for type $H$, it becomes:

$$
\begin{aligned}
\operatorname{LHS}_{\text {type } H}\left(w_{L}, w_{L}\right) & =\frac{1}{1-\delta} \frac{\left\{\left[u\left(w_{L}\right)+\beta p_{H} u\left(w_{L}\right)-u(z)-\beta p_{H} U_{I}\right]-\delta\left[u\left(w_{L}\right)+\beta p_{L} u\left(w_{L}\right)-u(z)-\beta p_{L} U_{I}\right]\right\}}{u^{\prime}\left(w_{L}\right)} \\
& =\underbrace{\frac{1}{1-\delta} \frac{\beta\left(p_{H}-p_{L}\right)\left[u\left(w_{L}\right)-U_{I}\right]}{u^{\prime}\left(w_{L}\right)}}_{>0}+\underbrace{\frac{\left[u\left(w_{L}\right)+\beta p_{L} u\left(w_{L}\right)-u(z)-\beta p_{L} U_{I}\right]}{u^{\prime}\left(w_{L}\right)}}_{=L H S_{\text {type } L}}
\end{aligned}
$$

Thus $L H S_{\text {type } H}\left(w_{L}, w_{L}\right)$ is always greater than the LHS of the FOC for type $L$, i.e. $L H S_{\text {type } H}\left(w_{L}, w_{L}\right)>\operatorname{LH} S_{\text {type } L}\left(w_{L}, w_{L}\right)$. But if it is so, then $\operatorname{LH} S_{\text {type } H}\left(w_{1, H}^{A I}, w_{2, H}^{A I}\right)>$ $L H S_{\text {type } H}\left(w_{L}, w_{L}\right)$, because we supposed $w_{L} \leq w_{1, H}^{A I}<w_{2, H}^{A I}$.

These will imply that the RHS of the FOC for type $H$ should be strictly greater than the RHS of the FOC for type $L$, i.e. $R H S_{\text {type } H}>R H S_{\text {type } L}$. Since the RHS of both FOCs have the same functional form, then it must be that $q_{H}^{A I}<q_{L}$, given that the RHS is decreasing in $q$. However, we established at the beginning of this proof that $q_{H}^{A I} \geq q_{L}$, we could reach the contradiction.

Claim 2b: $w_{H}<w_{2, H}^{A I}$. This could be shown using the same way as in the proof of claim 2a. Thus in total we have $w_{1, H}^{A I}<w_{L}<w_{H}<w_{2, H}^{A I}$.

Claim 3: $U_{H}^{I C}<U_{H}$. This is true because $U_{H}^{A I}$ is the utility at the maximum level of an optimization program with an additional constraint, compared to $U_{H}$.

\section{E Proof of Proposition 5}

Consider a pooling allocation which treats both types identically. All firms post $w_{1 \text { st period }}=$ $w_{2 \text { nd period }}=w_{\alpha}$. The queue length $q_{\alpha}=\alpha \frac{N}{M}+(1-\alpha) \frac{N}{M}=\frac{N_{H}}{M}+\frac{N_{L}}{M}$ will satisfy:

$$
H\left(q_{\alpha}\right)\left[\left(y-w_{\alpha}\right)+\beta p_{\alpha}\left(y-w_{\alpha}\right)\right]=C
$$

where $p_{\alpha}=\alpha p_{H}+(1-\alpha) p_{L}$. Furthermore, let $\left(q_{\alpha}, w_{\alpha}\right)$ be the solution of the following program:

$$
\begin{aligned}
U_{\alpha}= & \max F(q)\left[u\left(w_{\alpha}\right)+\beta p_{\alpha} u\left(w_{\alpha}\right)\right]+(1-F(q))\left(u(z)+\beta p_{\alpha} U_{I}\right) \\
\text { s.to } & H(q)\left[y-w_{\alpha}+\beta p_{\alpha}\left(y-w_{\alpha}\right)\right]=C
\end{aligned}
$$

If we compare the above zero profit condition $\left(H\left(q_{\alpha}\right)\left[\left(y-w_{\alpha}\right)+\beta p_{\alpha}\left(y-w_{\alpha}\right)\right]=C\right)$ to firms' zero profit condition in the separating equilibrium with asymmetric information, $H\left(q_{H}^{I C}\right)\left[\left(y-w_{1, H}^{I C}\right)+\beta p_{H}\left(y-w_{2, H}^{I C}\right)\right]=C$, we notice that, when $p_{\alpha} \rightarrow p_{H}$, i.e., when the fraction of bad workers is sufficiently low, the optimization program constructed just above approaches the optimization program for the type- $H$ workers in the full information (FI) case where IC constraint is absent. This implies that, when $p_{\alpha} \rightarrow p_{H}$, we obtain $w_{\alpha} \rightarrow w_{H}^{F I}$ and $q_{\alpha} \rightarrow q_{H}^{F I}$, hence the good workers will be better off in terms of expected utility, when the fraction of bad workers is negligible 
Furthermore, recall that in the full information case, the equilibrium allocation is such that $q_{H}^{F I}<q_{L}^{F I}$ and $w_{H}^{F I}>w_{L}^{F I}$. These two inequalities imply that the type $L$-workers could be employed more often, and receive higher ex post wages under this constructed pooling allocation. We could in turn conclude that the bad workers will also be better off in terms of expected utility under this pooling contract.

\section{F When all the workers choose to retire after 2 periods}

Firstly consider the case where both individuals are of type- $I$, where $h_{1}<h_{2} \leq \hat{h}^{F I}$, with $\hat{h}^{F I}$ being the threshold. In this situation, we have $\max \left\{U_{I}(h), U_{I I}(h)\right\}=U_{I I}(h), \forall h<\hat{h}^{F I}$. The optimal decisions are the solution of the following program:

$$
\begin{aligned}
U_{I I}= & \max _{q, w_{1}, w_{2}}\left\{F(q)\left[u\left(w_{1}\right)+\beta u\left(w_{2}\right)\right]+(1-F(q))\left[u(z)+\beta \max \left[U_{1 p}, u(h+z)\right]\right]\right\} \\
\text { s.to } & H(q)\left[y-w_{1}+\beta\left(y-w_{2}\right)\right] \geq C \\
U_{1 p}= & \max _{q, w}\{F(q) u(w)+(1-F(q)) u(z)\} \\
\text { s.to } & H(q)[y-w] \geq C
\end{aligned}
$$

We would like to make 2 remarks concerning this formulation:

- There is an important assumption we would like to adopt here: notice that $U_{1 p}$ is not defined as a function of $h$, because we would like to focus on the situation where the wages do not rise by virtue of the increase of home production level. This could also be interpreted as a re-evaluation of the retirement plan. In this case, with $U_{1 p}$ being not a function of $h$, we would have the property that workers who receive repeated short-term contracts earn constant wages.

- Implicitly, we are in the cases where $U_{I, h_{1}}=U_{1 p}+\beta u\left(h_{1}+z\right) \leq U_{I I, h_{1}}$, and $U_{I, h_{2}}=$ $U_{1 p}+\beta u\left(h_{2}+z\right) \leq U_{I I, h_{2}}$. This means that at the expected home production level $h_{1}<\hat{h}^{F I}$ and $h_{2}<\hat{h}^{F I}$, workers choose to work in the second period instead of retiring.

Proposition 14. The optimal allocation is characterized by (i) $w_{1}=w_{2}=w^{F I}$, (ii) $q=q^{F I}$ and $\frac{d w^{F I}}{d h} \geq 0$ and (iii) $\frac{d q^{F I}}{d h} \geq 0$ (Comparative statics).

Proof. Characteristic 1 (FOC):

It could be shown that the first order condition is such that $w_{1}=w_{2}=w^{F I}$, and

$$
\begin{aligned}
\frac{F^{\prime}\left(q^{F I}\right)}{H^{\prime}\left(q^{F I}\right)}(-1) \frac{C}{\left(y-w^{F I}\right)^{2}}(-1)\left[u\left(w^{F I}\right)-u(h+z)\right]+F\left(q^{F I}\right) u^{\prime}\left(w^{F I}\right) & =0 \\
\frac{\frac{\left[(1+\beta) u\left(w^{F I}\right)-u(z)-\beta \max \left[U_{1 p}, u(h+z)\right]\right]}{u^{\prime}\left(w^{F I}\right)}}{(1+\beta)\left(y-w^{F I}\right)} & =\frac{\epsilon_{H}\left(q^{F I}\right)}{1-\epsilon_{H}\left(q^{F I}\right)}
\end{aligned}
$$

Characteristic 2: $U_{I I, h_{1}}<U_{I I, h_{2}}$.

Proof: by Envelope theorem: 


$$
\frac{d U_{I I}}{d h}=1_{U_{1 p} \leq u(h+z)} \times \beta(1-F(q)) u^{\prime}(h+z) \geq 0
$$

where $1_{U_{1 p} \leq u(h+z)}$ is an indicator function such that $1_{U_{1 p} \leq u(h+z)}= \begin{cases}1 & \text { if } U_{1 p} \leq u(h+z) \\ 0 & \text { if } U_{1 p}>u(h+z)\end{cases}$

Subsequently, given $h_{1}<h_{2}$, we would obtain $U_{I I, h_{1}}<U_{I I, h_{2}}$.

Above is the sketch of the proof, because we made use the Envelope condition as a shortcut. Now we are going to give more details:

Specifically, we substitute out $q$ by the binding zero net profit constraint to obtain

$$
\begin{aligned}
U_{I I}(h+z)= & F\left(q^{F I}\left(w^{F I}\right)\right)\left[(1+\beta) u\left(w^{F I}\right)-u(z)-\beta \max \left[U_{1 p}, u(h+z)\right]\right] \\
& +\left[u(z)+\beta \max \left[U_{1 p}, u(h+z)\right]\right]
\end{aligned}
$$

and we differentiate with respect to $h$ at two sides, we obtain

$$
\begin{aligned}
\frac{\partial U_{I I}(h+z)}{\partial h}= & \underbrace{\left\{\frac{F^{\prime}\left(q^{F I}\right)}{H^{\prime}\left(q^{F I}\right)} \frac{C}{(1+\beta)\left(y-w^{F I}\right)^{2}}\left[\begin{array}{c}
\left.(1+\beta) u\left(w^{F I}\right)-u(z)-\beta \max \left[U_{1 p}, u(h+z)\right]\right] \\
+\beta F\left(q^{F I}\right) u^{\prime}\left(w^{F I}\right)
\end{array}\right\} \frac{d w^{F I}}{d h}\right.}_{=0 \text { by FOC }} \\
& +1_{U_{I} \leq u(h+z)} \times\left[-\beta F\left(q^{F I}\right) u^{\prime}(h+z)+\beta u^{\prime}(h+z)\right] \\
= & 1_{U_{I} \leq u(h+z)} \times \beta\left(1-F\left(q^{F I}\right)\right) u^{\prime}(h+z) \\
\geq & 0
\end{aligned}
$$

Characterstic 3 [comparative statics]: $\frac{d w^{F I}}{d h} \geq 0$ and $\frac{d q^{F I}}{d h} \geq 0$.

Proof: Consider the following implicit function obtained by rearranging the first order condition:

$X 1\left(w^{F I}, h\right)=u\left(w^{F I}\right)-\frac{1}{1+\beta} u(z)-\frac{\beta}{1+\beta} \max \left[U_{1 p}, u(h+z)\right]-u^{\prime}\left(w^{F I}\right)\left(y-w^{F I}\right) \frac{\epsilon_{H}\left(q\left(w^{F I}\right)\right)}{1-\epsilon_{H}\left(q\left(w^{F I}\right)\right)}=0$

where $q(w)$ defines $q$ as a function of $w$ by the binding zero net profit condition.

$$
\begin{aligned}
& \frac{d w^{F I}}{d h}=-\frac{X 1_{h}}{X 1_{w^{F I}}} \\
& =-\underbrace{\frac{1_{U_{I} \leq u(h+z) \frac{\beta}{1+\beta}}\left(-u^{\prime}(h+z)\right)}{u^{\prime}-u^{\prime \prime} \times(y-w) \times \frac{\epsilon_{H}}{1-\epsilon_{H}}-u^{\prime} \times(-1) \times \frac{\epsilon_{H}}{1-\epsilon_{H}}-u^{\prime} \times(y-w) \times\left(1-\epsilon_{H}\right)^{-2} \epsilon_{H}^{\prime} \times \frac{1}{H^{\prime}} \frac{C}{(y-w)^{2}}}}_{>0} \\
& \geq 0
\end{aligned}
$$

Analogously, consider the following implicit function $X 2\left(q^{F I}, h\right)=0$, where $X 2\left(q^{F I}, h\right)$ is obtained by rearranging the first order condition:

$X 2\left(q^{F I}, h\right)=u\left(w\left(q^{F I}\right)\right)-\frac{1}{1+\beta} u(z)-\frac{\beta}{1+\beta} \max \left[U_{1 p}, u(h+z)\right]-u^{\prime}\left(w\left(q^{F I}\right)\right)\left(y-w\left(q^{F I}\right)\right) \frac{\epsilon_{H}\left(q^{F I}\right)}{1-\epsilon_{H}\left(w\left(q^{F I}\right)\right)}$ 
where $w(q)$ defines $w$ as a function of $q$ by the binding zero net profit condition.

$$
\begin{aligned}
\frac{d q^{F I}}{d h} & =-\frac{X 2_{h}}{X 2_{q^{F I}}} \\
& =-\frac{1_{U_{I} \leq u(h+z) \frac{\beta}{1+\beta}\left(-u^{\prime}(h+z)\right)}}{u^{\prime}\left(\frac{C}{H^{2}} H^{\prime}\right)-u^{\prime \prime}\left(\frac{C}{H^{2}} H^{\prime}\right)(y-w) \frac{\epsilon_{H}}{1-\epsilon_{H}}-u^{\prime}\left(-\frac{C}{H^{2}} H^{\prime}\right) \frac{\epsilon_{H}}{1-\epsilon_{H}}-u^{\prime}(y-w)\left(1-\epsilon_{H}\right)^{-2} \epsilon_{H}^{\prime}} \\
& \geq 0
\end{aligned}
$$

Characteristic 4:

Although

$$
\begin{aligned}
& U_{I I, h_{1}}= \overbrace{F\left(q_{h_{1}}^{F I}\right)\left[(1+\beta) u\left(w_{h_{1}}^{F I}\right)-u(z)-\beta \max \left[U_{I}, u\left(h_{1}+z\right)\right]\right]}^{\text {constant }} \\
& U_{I I, h_{2}}= \underbrace{\mathrm{B} 1}_{\underbrace{F\left(q_{\left(q_{2}\right.}^{F I}\right)\left[(1+\beta)+\beta \max \left[U_{I}, u\left(h_{1}+z\right)\right]\right]}_{\text {constant }}} \\
&+\underbrace{\left[u(z)+\beta \max \left[U_{I}, u\left(h_{2}+z\right)\right]\right]}_{\mathrm{B} 2}
\end{aligned}
$$

We have

B1

$$
\begin{aligned}
& \overbrace{F\left(q_{h_{1}}^{F I}\right)\left[(1+\beta) u\left(w_{h_{1}}^{F I}\right)-u(z)-\beta \max \left[U_{I}, u\left(h_{1}+z\right)\right]\right]}^{\mathrm{V}} \\
& \underbrace{F\left(q_{h_{2}}^{F I}\right)\left[(1+\beta) u\left(w_{h_{2}}^{F I}\right)-u(z)-\beta \max \left[U_{I}, u\left(h_{2}+z\right)\right]\right]}_{\mathrm{B} 2}
\end{aligned}
$$

Proof: By the first order condition we have

$$
u\left(w^{F I}\right)-\frac{1}{1+\beta} u(z)-\frac{\beta}{1+\beta} \max \left[U_{1 p}, u(h+z)\right]=u^{\prime}\left(w^{F I}\right)\left(y-w^{F I}\right) \frac{\epsilon_{H}\left(q^{F I}\right)}{1-\epsilon_{H}\left(q^{F I}\right)}
$$

We use the RHS of this first order condition, i.e. $u^{\prime}\left(w^{F I}\right)\left(y-w^{F I}\right) \frac{\epsilon_{H}\left(q^{F I}\right)}{1-\epsilon_{H}\left(q^{F I}\right)}$, to substitute away the LHS of the first order condition, i.e. $u\left(w^{F I}\right)-\frac{1}{1+\beta} u(z)-\frac{\beta}{1+\beta} \max \left[U_{1 p}, u(h+z)\right]$, in the expressions "B1" and "B2". After this substitution we want to establish the following relationship:

$$
F\left(q_{h_{1}}^{F I}\right)\left[u^{\prime}\left(w_{h_{1}}^{F I}\right)\left(y-w_{h_{1}}^{F I}\right) \frac{\epsilon_{H}\left(q_{h_{1}}^{F I}\right)}{1-\epsilon_{H}\left(q_{h_{1}}^{F I}\right)}\right]>F\left(q_{h_{2}}^{F I}\right)\left[u^{\prime}\left(w_{h_{2}}^{F I}\right)\left(y-w_{h_{2}}^{F I}\right) \frac{\epsilon_{H}\left(q_{h_{2}}^{F I}\right)}{1-\epsilon_{H}\left(q_{h_{2}}^{F I}\right)}\right]
$$

This is confirmed by noticing the following two facts: 
(i) Since $\frac{d q^{F I}}{d h}>0$, we deduce $q_{h_{1}}^{F I}<q_{h_{2}}^{F I}$, hence $F\left(q_{h_{1}}^{F I}\right)>F\left(q_{h_{2}}^{F I}\right)$ and $\frac{\epsilon_{H}\left(q_{h_{1}}^{F I}\right)}{1-\epsilon_{H}\left(q_{h_{1}}^{F I}\right)}>$ $\frac{\epsilon_{H}\left(q_{h_{2}}^{F I}\right)}{1-\epsilon_{H}\left(q_{h_{2}}^{F I}\right)}$, since both $F(q)$ and $\frac{\epsilon_{H}(q)}{1-\epsilon_{H}(q)}$ are decreasing functions of $q$.

- Since $\frac{d w^{F I}}{d h}>0$, we deduce $w_{h_{1}}^{F I}<w_{h_{2}}^{F I}$, hence $u^{\prime}\left(w_{h_{1}}^{F I}\right)>u^{\prime}\left(w_{h_{2}}^{F I}\right)$ and $y-w_{h_{1}}^{F I}>$ $y-w_{h_{2}}^{F I}$, since both $u^{\prime}(w)$ and $y-w$ are decreasing functions of $w$.

Thus the characteristic 4 is obtained.

Characteristic 5:

a) the $h_{1}$-worker has no intention to claim that she is an $h_{2}$-worker.

b) the $h_{2}$-worker has no intention to claim that she is an $h_{1}$-worker;

Proof: Let us denote $U(\beta, z, h)=\left[u(z)+\beta \max \left[U_{1 p}, u(h+z)\right]\right]$, i.e. the outside option. We could rewrite to obtain the following expressions:

$$
\begin{aligned}
& U_{h_{1} \mid h_{1}}=F\left(q_{h_{1}}\right)\left[(1+\beta) u\left(w_{h_{1}}\right)-U\left(\beta, z, h_{1}\right)\right]+U\left(\beta, z, h_{1}\right) \\
& U_{h_{2} \mid h_{1}}=F\left(q_{h_{2}}\right)\left[(1+\beta) u\left(w_{h_{2}}\right)-U\left(\beta, z, h_{1}\right)\right]+U\left(\beta, z, h_{1}\right) \\
& U_{h_{2} \mid h_{2}}=F\left(q_{h_{2}}\right)\left[(1+\beta) u\left(w_{h_{2}}\right)-U\left(\beta, z, h_{2}\right)\right]+U\left(\beta, z, h_{2}\right) \\
& U_{h_{1} \mid h_{2}}=F\left(q_{h_{1}}\right)\left[(1+\beta) u\left(w_{h_{1}}\right)-U\left(\beta, z, h_{2}\right)\right]+U\left(\beta, z, h_{2}\right)
\end{aligned}
$$

utility of $h_{1}$-worker if she chooses to report truthfully her type utility of $h_{1}$-worker if she chooses to report that she is type- $h_{2}$-worker utility of $h_{2}$-worker if she chooses to report truthfully her type utility of $h_{2}$-worker if she chooses to report that she is type- $h_{1}$-worker

a) If the $h_{1}$-worker has the incentive to mimic the $h_{2}$-worker, we would expect that $U_{h_{2} \mid h_{1}}-U_{h_{1} \mid h_{1}}>0$. This is what we are going to negate now:

$$
\begin{aligned}
& U_{h_{2} \mid h_{1}}-U_{h_{1} \mid h_{1}}=F\left(q_{h_{2}}\right)\left[(1+\beta) u\left(w_{h_{2}}\right)-U\left(\beta, z, h_{1}\right)\right]-F\left(q_{h_{1}}\right)\left[(1+\beta) u\left(w_{h_{1}}\right)-U\left(\beta, z, h_{1}\right)\right] \\
& =F\left(q_{h_{2}}\right)[(1+\beta) u\left(w_{h_{2}}\right) \underbrace{-U\left(\beta, z, h_{2}\right)+U\left(\beta, z, h_{2}\right)}_{\text {add one term, substract one term }}-U\left(\beta, z, h_{1}\right)] \\
& -F\left(q_{h_{1}}\right)\left[(1+\beta) u\left(w_{h_{1}}\right)-U\left(\beta, z, h_{1}\right)\right] \\
& =U_{h_{2} \mid h_{2}}-U\left(\beta, z, h_{2}\right)-\left[U_{h_{1} \mid h_{1}}-U\left(\beta, z, h_{1}\right)\right]+F\left(q_{h_{2}}\right)\left[U\left(\beta, z, h_{2}\right)-U\left(\beta, z, h_{1}\right)\right] \\
& =\underbrace{U_{h_{2} \mid h_{2}}-U_{h_{1} \mid h_{1}}}_{>0, \text { since } \frac{d U}{d h}>0}-\underbrace{\left[1-F\left(q_{h_{2}}\right)\right]\left[U\left(\beta, z, h_{2}\right)-U\left(\beta, z, h_{1}\right)\right]}_{>0}
\end{aligned}
$$

It seems that the sign is ambiguous, but we now show that in fact the absolute value of the 1st term dominates.

Recall that in Characteristic 2, we established by the envelope condition that

$$
\frac{d U_{h \mid h}}{d h}=1_{U_{I} \leq u(h+z)} \times \beta\left(1-F\left(q^{F I}\right)\right) u^{\prime}(h+z)
$$


Thus we integrate at two sides:

$$
\int \frac{d U_{h \mid h}}{d h} d h=\int 1_{U_{I} \leq u(h+z)} \times \beta\left(1-F\left(q^{F I}\right)\right) u^{\prime}(h+z) d h
$$

hence

$$
\begin{aligned}
U_{h_{2} \mid h_{2}}-U_{h_{1} \mid h_{1}}= & \int_{h_{1}}^{h_{2}} 1_{U_{I} \leq u(h+z)} \times \beta(1-F(q)) u^{\prime}(h+z) d h \\
& \downarrow(\text { intergration by parts }) \\
= & {\left.\left[1_{U_{I} \leq u(h+z)} \times \beta(1-F(q)) u(h+z)\right]\right|_{h_{1}} ^{h_{2}} } \\
& -\beta \int_{h_{1}}^{h_{2}} 1_{U_{I} \leq u(h+z)} u(h+z) d(1-F(q))
\end{aligned}
$$

Thus we could have

$$
\begin{aligned}
U_{h_{2} \mid h_{1}}-U_{h_{1} \mid h_{1}}= & \underbrace{U_{h_{2} \mid h_{2}}-U_{h_{1} \mid h_{1}}}_{>0, \text { since } \frac{d U}{d h}>0}-\underbrace{\left[1-F\left(q_{h_{2}}\right)\right]\left[U\left(\beta, z, h_{2}\right)-U\left(\beta, z, h_{1}\right)\right]}_{>0} \\
= & \overbrace{\left.\left[1_{U_{I} \leq u(h+z)} \times \beta(1-F(q)) u(h+z)\right]\right|_{h_{1}} ^{h_{2}}}^{\mathrm{D} 1} \\
& -\underbrace{\beta \int_{h_{1}}^{h_{2}} 1_{U_{I} \leq u(h+z)} u(h+z) d(1-F(q))}_{\mathrm{D} 2} \\
= & 1_{U_{I} \leq u(h+z)}^{\left[1-F\left(q_{h_{2}}\right)\right]\left[U\left(\beta, z, h_{2}\right)-U\left(\beta, z, h_{1}\right)\right]} \\
= & 1_{U_{I} \leq u(h+z)} \times \beta\{\underbrace{(\operatorname{we} \operatorname{could} \operatorname{merge~D} 1 \text { and D } 3)}_{\mathrm{D} 3}
\end{aligned}
$$

We conclude that $\left\{\left[F\left(q_{1}\right)-F\left(q_{2}\right)\right] u\left(h_{1}\right)+\int_{h_{1}}^{h_{2}} u(h+z) d F(q)\right\}<0$, because

$$
\int_{h_{1}}^{h_{2}} u(h+z) d F(q)=\int_{h_{1}}^{h_{2}} u(h+z) \underbrace{F^{\prime}(q)}_{<0} \frac{d q}{d h} d h<\int_{h_{1}}^{h_{2}} u\left(h_{1}+z\right) F^{\prime}(q) \frac{d q}{d h} d h=\left[F\left(q_{2}\right)-F\left(q_{1}\right)\right] u\left(h_{1}\right)
$$

b) Analogously, If the $h_{2}$-worker has an incentive to mimic the $h_{1}$-worker, we would expect that $U_{h_{1} \mid h_{2}}-U_{h_{2} \mid h_{2}}>0$. This is what we are going to compute now: 


$$
\begin{aligned}
U_{h_{1} \mid h_{2}}-U_{h_{2} \mid h_{2}}= & \underbrace{U_{h_{2} \mid h_{2}}-U_{h_{1} \mid h_{1}}}_{>0, \text { since } \frac{d U}{d h}>0}-\underbrace{\left[1-F\left(q_{h_{2}}\right)\right]\left[U\left(\beta, z, h_{2}\right)-U\left(\beta, z, h_{1}\right)\right]}_{>0} \\
= & \overbrace{\left.\left[1_{U_{I} \leq u(h+z)} \times \beta(1-F(q)) u(h+z)\right]\right|_{h_{1}} ^{h_{2}}}^{\mathrm{D} 1} \\
& -\underbrace{\beta \int_{h_{1}}^{h_{2}} 1_{U_{I} \leq u(h+z)} u(h+z) d(1-F(q))}_{\mathrm{D} 2} \\
= & 1_{U_{I} \leq u(h+z)}^{\left[1-F\left(q_{h_{2}}\right)\right]\left[U\left(\beta, z, h_{2}\right)-U\left(\beta, z, h_{1}\right)\right]} \\
= & 1_{U_{I} \leq u(h+z)} \times \beta \underbrace{\left\{\left[F\left(q_{2}\right)-F\left(q_{1}\right)\right] u\left(h_{2}+z\right)+\int_{h_{2}}^{h_{1}} u(h+z) d F(q)\right\}}_{\mathrm{D} 3\left(F\left(q_{1}\right)-F\left(q_{2}\right)\right] u\left(h_{1}\right)-\mathrm{D} 2}
\end{aligned}
$$

we could conclude that $\left\{\left[F\left(q_{2}\right)-F\left(q_{1}\right)\right] u\left(h_{2}\right)+\int_{h_{2}}^{h_{1}} u(h+z) d F(q)\right\}<0$, because

$$
\int_{h_{2}}^{h_{1}} u(h+z) d F(q)=\int_{h_{2}}^{h_{1}} u(h+z) \underbrace{F^{\prime}(q)}_{<0} \frac{d q}{d h} d h<\int_{h_{2}}^{h_{1}} u\left(h_{2}+z\right) F^{\prime}(q) \frac{d q}{d h} d h=\left[F\left(q_{1}\right)-F\left(q_{2}\right)\right] u\left(h_{1}\right)
$$

We thus conclude that there would be no information problem if two types both want to work for two periods.

Lemma 2. The optimal allocation is thus characterized by a unique labor market by age.

Proof. Trivial implication of Propositions 14 and 1.

\section{G When all the workers choose to retire in period 1}

We now consider the case where all individuals are of type- $I$, where $\hat{h}^{F I}<h_{1}<h_{2}$, with $\hat{h}^{F I}$ being the threshold. The expected home production levels are high, such that all the workers choose to retire instead of working in the second period. In this case the allocation is the solution of the following program:

$$
\begin{aligned}
& U_{I}= \max _{q, w}\{F(q) u(w)+(1-F(q)) u(z)+\beta u(h+z)\} \\
& \text { s.to } \quad H(q)[y-w] \geq C
\end{aligned}
$$

Notice that, implicitly we have $U_{I}=U_{1 p}+\beta u(h+z)>U_{I I}$.

Proposition 15. The optimal allocations have the following properties: (i) $(w, q)$ the optimal allocation is independent of $h$, (ii) $U_{I, h_{1}}<U_{I, h_{2}}$, and (iii) $\frac{d w^{F I}}{d h}=0$ and $\frac{d q^{F I}}{d h}=0$ (Comparative statics). 
Proof. Characteristic 1 (FOC): $(w, q)$ the optimal allocation is independent of $h$.

It could be shown that the first order condition is such that

$$
\begin{aligned}
\frac{F^{\prime}\left(q^{F I}\right)}{H^{\prime}\left(q^{F I}\right)}(-1) \frac{C}{\left(y-w^{F I}\right)^{2}}(-1)\left[u\left(w^{F I}\right)-u(h+z)\right]+F\left(q^{F I}\right) u^{\prime}\left(w^{F I}\right) & =0 \\
\Rightarrow \frac{\frac{\left[u\left(w^{F I}\right)-u(z)\right.}{u^{\prime}\left(w^{F I}\right)}}{\left(y-w^{F I}\right)} & =\frac{\epsilon_{H}\left(q^{F I}\right)}{1-\epsilon_{H}\left(q^{F I}\right)}
\end{aligned}
$$

Characteristic 2: $U_{I, h_{1}}<U_{I, h_{2}}$.

Proof: by envelop condition, $\frac{d U_{I I}}{d h}=\beta u^{\prime}(h+z)>0$. Since $h_{1}<h_{2}$, we would obtain $U_{I, h_{1}}<U_{I, h_{2}}$.

Characteristic 3 [comparative statics]: $\frac{d w^{F I}}{d h}=0$ and $\frac{d q^{F I}}{d h}=0$.

Proof: Consider the following implicit function obtained by rearranging the FOC:

$$
X 1\left(w^{F I}, h\right)=u\left(w^{F I}\right)-u(z)-u^{\prime}\left(w^{F I}\right)\left(y-w^{F I}\right) \frac{\epsilon_{H}\left(q\left(w^{F I}\right)\right)}{1-\epsilon_{H}\left(q\left(w^{F I}\right)\right)}=0
$$

where $q(w)$ defines $q$ as a function of $w$ by the binding zero net profit condition. Using this implicit function, we deduce that:

$$
\begin{aligned}
\frac{d w^{F I}}{d h} & =-\frac{X 1_{h}}{X 1_{w^{F I}}} \\
& =-\frac{0}{u^{u^{\prime}-u^{\prime \prime}(y-w) \frac{\epsilon_{H}}{1-\epsilon_{H}}-u^{\prime}(-1) \frac{\epsilon_{H}}{1-\epsilon_{H}}-u^{\prime}(y-w)\left(1-\epsilon_{H}\right)^{-2} \epsilon_{H}^{\prime} \frac{1}{H^{\prime}} \frac{C}{(y-w)^{2}}}} \\
& =0
\end{aligned}
$$

Analogously, $\frac{d q^{F I}}{d h}=0$. These results imply that $\left(w_{h_{1}}, q_{h_{1}}\right)=\left(w_{h_{2}}, q_{h_{2}}\right)$. We thus could conclude that there would be no information problem if two types both wanted to work only for 1 period.

\section{H Proof of Proposition 6}

Denote

$$
\begin{aligned}
U_{h_{I I} \mid h_{I}} & =F\left(q_{I I}\right) u\left(w_{I I}\right)+\left(1-F\left(q_{I I}\right)\right) u(z)+\beta u\left(h_{I}\right) \\
U_{h_{I} \mid h_{I}} & =F\left(q_{I}\right) u\left(w_{I}\right)+\left(1-F\left(q_{I}\right)\right) u(z)+\beta u\left(h_{I}\right)
\end{aligned}
$$

The type- $I$ workers have an incentive to mimic the type- $I I$ workers iff $U_{h_{I I} \mid h_{I}}>U_{h_{I} \mid h_{I}}$. When $h_{I I}=0, U_{h_{I I} \mid h_{I}}$ and $U_{h_{I} \mid h_{I}}$ coincide. Furthermore, when $h_{I I}>\hat{h}, U_{h_{I I} \mid h_{I}}$ and $U_{h_{I} \mid h_{I}}$ also coincide. It thus is sufficient to show that $U_{h_{I I} \mid h_{I}}$ is concave, so that, for any $0<h_{I I}<\hat{h}$, 
this inequality holds ${ }^{21}$. We differentiate $U_{h_{I I} \mid h_{I}}$ with respect to $h_{I I}$ twice, we could obtain that:

$$
\begin{aligned}
\frac{d U_{h_{I I} \mid h_{I}}}{d h_{I I}}= & F^{\prime} \frac{d q_{I I}}{d h_{I I}}\left[u\left(w_{I I}\right)-u(z)\right]+F u^{\prime}\left(w_{I I}\right) \frac{d w_{I I}}{d h_{I I}} \\
\frac{d^{2} U_{h_{I I} \mid h_{I}}}{d h_{I I}^{2}}= & {\left[F^{\prime \prime}\left(\frac{d q_{I I}}{d h_{I I}}\right)^{2}+F^{\prime} \frac{d^{2} q_{I I}}{d h_{I I}^{2}}\right]\left[u\left(w_{I I}\right)-u(z)\right]+F^{\prime} \frac{d q_{I I}}{d h_{I I}} u^{\prime}\left(w_{I I}\right) \frac{d w_{I I}}{d h_{I I}} } \\
& +F^{\prime} \frac{d q_{I I}}{d h_{I I}} u^{\prime}\left(w_{I I}\right) \frac{d w_{I I}}{d h_{I I}}+F\left[u^{\prime \prime}\left(\frac{d w_{I I}}{d h_{I I}}\right)^{2}+u^{\prime} \frac{d^{2} w_{I I}}{d h_{I I}^{2}}\right]
\end{aligned}
$$

By implicit function theorem, it is ready to be checked that if $\frac{d^{2} q_{I I}}{d h_{I I}^{2}}>0$ and $\frac{d^{2} w_{I I}}{d h_{I I}^{2}}<0$, $\frac{d^{2} U_{h_{I I} \mid h_{I}}}{d h_{I I}^{2}}<0$ which implies that the function $U_{h_{I I} \mid h_{I}}$ is concave, or precisely it is first increasing than decreasing and admits a unique maximum.

\section{Proof of Proposition 7}

The first order conditions with respect to $w_{I I, 1}, w_{I I, 2}$ and $q_{I I}$ are:

$$
\begin{aligned}
F\left(q_{I I}\right) u^{\prime}\left(w_{I I, 1}\right)-\lambda H\left(q_{I I}\right)-\delta F\left(q_{I I}\right) u^{\prime}\left(w_{I I, 1}\right) & =0 \\
F\left(q_{I I}\right) u^{\prime}\left(w_{I I, 2}\right)-\lambda H\left(q_{I I}\right) & =0 \\
F^{\prime}\left(q_{I I}\right)\left[u\left(w_{I I, 1}\right)-u(z)\right]+\beta F^{\prime}\left(q_{I I}\right)\left[u\left(w_{I I, 2}\right)-u(h+z)\right] & \\
+\lambda H^{\prime}\left(q_{I I}\right)\left[y-w_{I I, 1}+\beta\left(y-w_{I I, 2}\right)\right]-\delta F^{\prime}\left(q_{I I}\right)\left[u\left(w_{I I, 1}\right)-u(z)\right] & =0
\end{aligned}
$$

where $\lambda$ and $\delta$ are the Lagrangian multipliers associated with the first and the second constraint. Given that $H(q) / F(q)=q$, the FOC leads to

$$
\begin{aligned}
u^{\prime}\left(w_{I I, 1}\right) & =\frac{\lambda}{1-\delta} q_{I I}^{A I} \\
u^{\prime}\left(w_{I I, 2}\right) & =\lambda q_{I I}^{A I}
\end{aligned}
$$

implying that $w_{I I, 1}<w_{I I, 2}$. Suppose that $w_{I I, 1} \geq w_{I I}^{F I}$, then since $w_{I I, 2}>w_{I I, 1}$, we have $w_{I I, 2}>w_{I I, 1} \geq w_{I I}^{F I}$. On the one hand, by the binding zero profit conditions

$$
\begin{aligned}
H\left(q_{I I}^{F I}\right)\left((1+\beta) y-w_{I I}^{F I}-\beta w_{I I}^{F I}\right) & =0 \\
H\left(q_{I I}\right)\left((1+\beta) y-w_{I I, 1}-\beta w_{I I, 2}\right) & =0
\end{aligned}
$$

\footnotetext{
${ }^{21}$ The value of $\hat{h}$ is determined in such a way that the worker who is indifferent about working in the 2nd period or not, that is to say: the worker $\hat{h}$ such that $U_{I}\left(\hat{h}^{F I}+z\right)=U_{1 p}+\beta u\left(\hat{h}^{F I}+z\right)=U_{I I}\left(\hat{h}^{F I}+z\right)$.
} 
we conclude that $q_{I I}>q_{I I}^{F I}$. But, on the other hand, by the first order condition with respect to $q$, which could be rewritten in the following fashion,

$$
\begin{aligned}
\frac{u\left(w_{I I}^{F I}\right)-u(z)}{u^{\prime}\left(w_{I I}^{F I}\right)}+\beta \frac{u\left(w_{I I}^{F I}\right)-u(h+z)}{u^{\prime}\left(w_{I I}^{F I}\right.} & =\frac{\epsilon\left(q_{I I}^{F I}\right)}{1-\epsilon\left(q_{I I}^{F I}\right)} \frac{C}{H\left(q_{I I}^{F I}\right)} \\
\frac{u\left(w_{I I, 1}\right)-u(z)}{u^{\prime}\left(w_{I I, 1}\right)}+\beta \frac{u\left(w_{I I, 2}\right)-u(h+z)}{u^{\prime}\left(w_{I I, 2}\right)} & =\frac{\epsilon\left(q_{I I}\right)}{1-\epsilon\left(q_{I I}\right)} \frac{C}{H\left(q_{I I}\right)}
\end{aligned}
$$

we could conclude that $q_{I I}<q_{I I}^{F I}$, because $\Phi(w) \equiv \frac{u(w)-u(z)}{u^{\prime}(w)}$ is increasing in $w$ and $\Psi(q) \equiv$ $\frac{\epsilon(q)}{1-\epsilon(q)} \frac{C}{H(q)}$ is decreasing in $q$. Obviously, these two lead us to a contradiction. To prove $w_{I I}^{F I}<w_{I I, 2}$, we could proceed by using exactly the same argument.

Finally, if we look at the IC constraint, we have

$$
\begin{aligned}
F\left(q_{I I}^{A I}\right) u\left(w_{I I, 1}\right)+\left(1-F\left(q_{I I}^{A I}\right)\right) u(z) & =U_{I}\left(h_{I}\right) \\
& =F\left(q_{I}\right) u\left(w_{I}\right)+\left(1-F\left(q_{I}\right)\right) u(z)
\end{aligned}
$$

Given that the utility $u($.$) is an increasing function of its argument and the job finding rate$ $F($.$) is decreasing in its argument, we could reach q_{I I}^{A I}<q_{I}^{A I}=q_{I}$.

\section{J Proof of Lemma 1}

For (i), recall that we just obtained the FOC as

$$
\left.J_{\tilde{h}}(h, \tilde{h})\right|_{\tilde{h}=h}=e_{I I}^{\prime}(h) u\left(W_{2}(h)\right)+e_{I I}(h) u^{\prime}\left(W_{2}(h)\right) W_{2}^{\prime}(h)-e_{I I}^{\prime}(h) u(h+z)=0
$$

We now integrate this equation with respect to $h$

$$
\begin{aligned}
\left.\int_{h}^{\bar{h}} J_{\tilde{h}}(h, \tilde{h})\right|_{\tilde{h}=h} d h & =e_{I I}(\bar{h}) u\left(W_{2}(\bar{h})\right)-e_{I I}(h) u\left(W_{2}(h)\right)-\int_{h}^{\bar{h}} u(\tau+z) d e_{I I}(\tau) \\
& =e_{I I}(\bar{h}) u\left(W_{2}(\bar{h})\right)-e_{I I}(h) u\left(W_{2}(h)\right)-\left.\left[u(h+z) e_{I I}(h)\right]\right|_{h} ^{\bar{h}}+\int_{h}^{\bar{h}} e_{I I}(\tau) u^{\prime}(\tau+z) d \tau
\end{aligned}
$$

Rearranged, we could obtain $J(h, h)=J(\bar{h}, \bar{h})+\int_{h}^{\bar{h}} e_{I I}(\tau) u^{\prime}(\tau+z) d \tau$.

For (ii), since $J(h, h)$ is decreasing in $h$, thus as long as $J(\bar{h}, \bar{h}) \geq 0$, then for all $h<\bar{h}$, $J(h, h)>0$. This can be rewritten as follows:

$$
J(\bar{h}, \bar{h})=J(h, h)-\int_{h}^{\bar{h}} e_{I I}(\tau) u^{\prime}(\tau+z) d \tau \geq 0
$$

We integrate this equation above in the following way to obtain,

$$
\int_{\underline{h}}^{\bar{h}} J(\bar{h}, \bar{h}) d G(h)=\int_{\underline{h}}^{\bar{h}} J(h, h) d G(h)-\int_{\underline{h}}^{\bar{h}}\left[\int_{h}^{\bar{h}} e_{I I}(\tau) u^{\prime}(\tau+z) d \tau\right] d G(h) \geq 0
$$


We thus deduce

$$
\begin{aligned}
& \int_{\underline{h}}^{\bar{h}} J(h, h) d G(h)-\int_{\underline{h}}^{\bar{h}}\left[\int_{h}^{\bar{h}} e_{I I}(\tau) u^{\prime}(\tau+z) d \tau\right] d G(h) \geq 0 \\
& \Leftrightarrow \int_{\underline{h}}^{\bar{h}} J(h, h) d G(h)-\int_{\underline{h}}^{\bar{h}} \frac{G(h)}{g(h)} e_{I I}(h) u^{\prime}(h+z) d G(h) \geq 0
\end{aligned}
$$

Using the definition of $J(h, h)=e_{I I}(h) u\left(W_{2}(h)\right)-e_{I I}(h) u(h+z)$ and integration by parts, we finally obtain IR'.

\section{K Proof of Proposition 9}

We would like to check how the welfare $U^{\text {pooling }}$ varies with respect to the fraction of type $I I$ workers. By the envelope condition, we obtain:

$$
\begin{aligned}
\frac{\partial U^{\text {pooling }}}{\partial \alpha}= & \beta F(\hat{q}) u\left(\hat{w}_{2}\right)+\beta[1-F(\hat{q})] \max \left\{u\left(h_{I I}+z\right), U_{1 p}\right\}-\beta u\left(h_{I}+z\right) \\
& +\lambda\left\{F(\hat{q}) \beta\left(y-\hat{w}_{2}\right)\right\}
\end{aligned}
$$

where the endogenous variables with hat represent the optimal allocation, and $\lambda$ represents the Lagrangian multiplier attached to the zero profit constraint. By the FOC, we have $u^{\prime}(\hat{w})=\lambda \hat{q}$, which could help us to substitute out the $\lambda$. Accordingly, the above expression could be rewritten in the following fashion:

$\frac{\partial U^{\text {pooling }}}{\partial \alpha}=\beta F(\hat{q}) u^{\prime}\left(\hat{w}_{2}\right)\left[\frac{u\left(\hat{w}_{2}\right)-\max \left[U_{1 p}, u\left(h_{I I}+z\right)\right]}{u^{\prime}\left(\hat{w}_{2}\right)}+\frac{\max \left[U_{1 p}, u\left(h_{I I}+z\right)\right]-u\left(h_{I}+z\right)}{u^{\prime}\left(\hat{w}_{2}\right) F(\hat{q})}+\left(y-\hat{w}_{2}\right)\right]$

We now want to show that it is possible that for some values of $h_{I}$, this derivative could be negative.

Notice that, $\max \left[U_{1 p}, u\left(h_{I I}+z\right)\right]-u\left(h_{I}+z\right)<0$. Hence the term $\frac{\max \left[U_{1 p}, u\left(h_{I I}+z\right)\right]-u\left(h_{I}+z\right)}{u^{\prime}\left(\hat{w}_{2}\right) F(\hat{q})}<$ $\frac{\max \left[U_{1 p}, u\left(h_{I I}+z\right)\right]-u\left(h_{I}+z\right)}{u^{\prime}\left(\hat{w}_{2}\right)}$ by virtue of the fact that $0<F(\hat{q})<1$. We hence obtain the following relationship:

$$
\begin{aligned}
\frac{\partial U^{\text {pooling }}}{\partial \alpha} & =\beta F(\hat{q}) u^{\prime}\left(\hat{w}_{2}\right)\left[\frac{\left[u\left(\hat{w}_{2}\right)-\max \left[U_{1 p}, u\left(h_{I I}+z\right)\right]\right]}{u^{\prime}\left(\hat{w}_{2}\right)}+\frac{\max \left[U_{1 p}, u\left(h_{I I}+z\right)\right]-u\left(h_{I}+z\right)}{u^{\prime}\left(\hat{w}_{2}\right) F(\hat{q})}+\left(y-\hat{w}_{2}\right)\right] \\
& \leq \beta F(\hat{q}) u^{\prime}\left(\hat{w}_{2}\right)\left[\frac{\left[u\left(\hat{w}_{2}\right)-\max \left[U_{1 p}, u\left(h_{I I}+z\right)\right]\right]}{u^{\prime}\left(\hat{w}_{2}\right)}+\frac{\max \left[U_{1 p}, u\left(h_{I I}+z\right)\right]-u\left(h_{I}+z\right)}{u^{\prime}\left(\hat{w}_{2}\right)}+\left(y-\hat{w}_{2}\right)\right] \\
& =\beta F(\hat{q})\left[\left[u\left(\hat{w}_{2}\right)-\max \left[U_{1 p}, u\left(h_{I I}+z\right)\right]\right]+\max \left[U_{1 p}, u\left(h_{I I}+z\right)\right]-u\left(h_{I}+z\right)+u^{\prime}\left(\hat{w}_{2}\right)\left(y-\hat{w}_{2}\right)\right] \\
& =\beta F(\hat{q})\left[u\left(\hat{w}_{2}\right)-u\left(h_{I}+z\right)+u^{\prime}\left(\hat{w}_{2}\right)\left(y-\hat{w}_{2}\right)\right]
\end{aligned}
$$

In order to show that $\frac{\partial U^{\text {pooling }}}{\partial \alpha}$ could take negative values, it suffices to determine the sign of $\left[u\left(\hat{w}_{2}\right)-u\left(h_{I}+z\right)+u^{\prime}\left(\hat{w}_{2}\right)\left(y-\hat{w}_{2}\right)\right]$. 
Let us define $A(w):=\left[u\left(\hat{w}_{2}\right)-u\left(h_{I}+z\right)+u^{\prime}\left(\hat{w}_{2}\right)\left(y-\hat{w}_{2}\right)\right]$. We notice that $u(w)+$ $u^{\prime}(w)(y-w)$ is a decreasing function of $w$, since its derivative is inferior to zero, i.e., $\frac{d}{d w}\left[u(w)+u^{\prime}(w)(y-w)\right]=u^{\prime \prime}(w)(y-w)<0$. We also know that $\hat{w}_{2}$ could only take values in the interval $[0, y]$.

To check whether $\frac{\partial U^{\text {pooling }}}{\partial \alpha}$ could take negative values, it suffices to study whether the function $A(w)$ and $u\left(h_{I}+z\right)$ may intersect at some point $w \in[0, y]$.

When $\hat{w}_{2}=y,\left[u\left(\hat{w}_{2}\right)-u\left(h_{I}+z\right)+u^{\prime}\left(\hat{w}_{2}\right)\left(y-\hat{w}_{2}\right)\right]_{\hat{w}_{2}=y}=u(y)-u\left(h_{I}+z\right)$. Hence it is evident that for sufficiently large values of $h$, such that $y<h+z$, the sign of this expression could be negative, hence $\frac{\partial U^{\text {pooling }}}{\partial \alpha}$ could be negative.

Notice that a similar argument applies to show that for mild values of $h_{I}$, the $\frac{\partial U^{\text {pooling }}}{\partial \alpha}$ could be always positive. To see this, we notice that the value of the term $\frac{\max \left[U_{1 p}, u\left(h_{I I}+z\right)\right]-u\left(h_{I}+z\right)}{u^{\prime}\left(\hat{w}_{2}\right) F(\hat{q})}$ is bounded and that $\left[u(w)+u^{\prime}(w)(y-w)\right]$ could take large values when $w$ is small enough, as long as we assume $u^{\prime}(w)$ could take sufficiently large values when $w \rightarrow 0$.

\section{Proof of Proposition 10}

Recall that the program could be written as follows,

$$
\begin{aligned}
U^{\text {pooling }}= & \max \left\{\begin{array}{l}
F(q) u\left(w_{1}\right)+[1-F(q)] u(z) \\
+\alpha\left\{\beta F(q) u\left(w_{2}\right)+\beta[1-F(q)] \max \left\{u\left(h_{I I}+z\right), U_{1 p}\right\}\right\}+(1-\alpha) \beta u\left(h_{I}+z\right)
\end{array}\right\} \\
\text { s.t. } & F(q)\left[y-w_{1}+\alpha \beta\left(y-w_{2}\right)\right] \geq \frac{C}{q}
\end{aligned}
$$

and that we are in the case where the $\frac{\partial U^{\text {pooling }}}{\partial \alpha}$ is always positive, i.e.,

$$
\begin{aligned}
\frac{\partial U^{\text {pooling }}}{\partial \alpha} & =\beta F(\hat{q}) u^{\prime}\left(\hat{w}_{2}\right)\left[\frac{\left[u\left(\hat{w}_{2}\right)-\max \left[U_{1 p}, u\left(h_{I I}+z\right)\right]\right]}{u^{\prime}\left(\hat{w}_{2}\right)}+\frac{\max \left[U_{1 p}, u\left(h_{I I}+z\right)\right]-u\left(h_{I}+z\right)}{u^{\prime}\left(\hat{w}_{2}\right) F(\hat{q})}+\left(y-\hat{w}_{2}\right)\right] \\
& >0
\end{aligned}
$$

We want to show that when $\alpha$ approaches to one, $U^{\text {pooling }}>U^{\text {separating }}$.

It is readily observed that, in the objective function, the term $(1-\alpha) \beta u\left(h_{I}+z\right)$ tends to zero, and at the same time, the program tends to the program for a type- $I I$ worker without the incentive constraint. These two observations imply that in this situation, when $\alpha \rightarrow 1$, the welfare of type $I I$ workers can be raised.

Now we need to show that the expected utility of the type- $I$ workers is not decreased, compared to the case with asymmetric information. In fact, we can show that the expected utility of the type- $I$ workers will increase, because of the following two comparative statics $\left.\frac{d w_{1}^{\text {optimal }}}{d \alpha}\right|_{\alpha \rightarrow 1}>0$ and $\left.\frac{d q^{\text {optimal }}}{d \alpha}\right|_{\alpha \rightarrow 1}<0$. In order to show $\left.\frac{d w_{1}^{\text {optimal }}}{d \alpha}\right|_{\alpha \rightarrow 1}>0$ and $\left.\frac{d q^{\text {optimal }}}{d \alpha}\right|_{\alpha \rightarrow 1}<$ 0 , we first write down the two equations (First order condition and the Free entry condition) which pin down the equilibrium allocation.

$$
\begin{aligned}
F^{\prime}(q)\left\{\begin{array}{l}
u(w)-u(z) \\
+\alpha \beta\left[u\left(w_{2}\right)-\max \left\{u\left(h_{I I}+z\right), U_{1 p}\right\}\right]
\end{array}\right\} & =-\frac{u^{\prime}(w)}{q} H^{\prime}(q) \frac{C}{H(q)} \\
F(q)\left[y-w_{1}+\alpha \beta\left(y-w_{2}\right)\right] & =\frac{C}{q}
\end{aligned}
$$


This leads us to the same system of implicit functions which we considered in the first section, if we consider $\alpha \beta=\tilde{\beta}$. Since it was established that $\frac{d w_{1}^{\text {optimal }}}{d \tilde{\beta}}>0$ and $\frac{d q^{\text {optimal }}}{d \tilde{\beta}}<0$ (see Appendix A, proof of Proposition 1), here if we regard $\beta$ as the constant and $\alpha$ as the variable, we could reach the desired results.

Since the welfare of both types of workers can be raised, this pooling scheme Pareto dominates the previous separating scheme.

\section{Proof of Proposition 11}

First of all, Proposition 10 shows that $\hat{h}^{I C}<\hat{h}^{F I}$.

In the second place, we prove $\hat{h}_{\alpha \rightarrow 1}^{\text {pooling }}<\hat{h}^{F I}$. By definition, we should have $U_{I I}^{\text {pooling }}\left(\hat{h}_{\alpha \rightarrow 1}^{\text {pooling }}+\right.$ $z)=U_{I}\left(\hat{h}_{\alpha \rightarrow 1}^{\text {pooling }}+z\right)$ and $U_{I I}^{F I}\left(\hat{h}^{F I}+z\right)=U_{I}\left(\hat{h}^{F I}+z\right)$. Now suppose that $\hat{h}_{\alpha \rightarrow 1}^{\text {pooling }} \geq \hat{h}^{F I}$. This implies that $U_{I I}^{\text {pooling }}\left(\hat{h}^{F I}+z\right) \geq U_{I}\left(\hat{h}^{F I}+z\right)$, i.e., the type $\hat{h}^{F I}$ under the pooling scheme will not choose to retire. However, this further implies that $U_{I I}^{\text {pooling }}\left(\hat{h}^{F I}+z\right) \geq U_{I}\left(\hat{h}^{F I}+z\right)=$ $U_{I I}^{F I}\left(\hat{h}^{F I}+z\right)$. This is impossible for the following reasons: (i) when $\alpha=1$, these two programs coincide, (ii) given that $\frac{\partial U^{\text {pooling }}}{\partial \alpha}>0$, when $\alpha \rightarrow 1$ but never reaches 1 , we should thus obtain $U_{I I}^{\text {pooling }}<U_{I I}^{F I}$ for any level of $h$.

In the third place, we establish $\hat{h}^{I C}<\hat{h}_{\alpha \rightarrow 1}^{\text {pooling }}$. By definition, we should have $U_{I I}^{I C}\left(\hat{h}^{I C}+\right.$ $z)=U_{I}\left(\hat{h}^{I C}+z\right)$ and $U_{I I}^{\text {pooling }}\left(\hat{h}_{\alpha \rightarrow 1}^{\text {pooling }}+z\right)=U_{I}\left(\hat{h}_{\alpha \rightarrow 1}^{\text {pooling }}+z\right)$. We suppose that $\hat{h}^{I C} \geq \hat{h}_{\alpha \rightarrow 1}^{\text {pooling }}$. This implies that $U_{I I}^{I C}\left(\hat{h}_{\alpha \rightarrow 1}^{\text {pooling }}+z\right) \geq U_{I}\left(\hat{h}_{\alpha \rightarrow 1}^{\text {pooling }}+z\right)$, i.e., the type $\hat{h}_{\alpha \rightarrow 1}^{\text {pooling }}$ under the separating scheme will not choose to retire. However, this readily implies that $U_{I I}^{I C}\left(\hat{h}_{\alpha \rightarrow 1}^{\text {pooling }}+z\right) \geq$ $U_{I}\left(\hat{h}_{\alpha \rightarrow 1}^{\text {pooling }}+z\right)=U_{I I}^{\text {pooling }}\left(\hat{h}_{\alpha \rightarrow 1}^{\text {pooling }}+z\right)$. This is impossible, because as we have shown in the previous result that when $\alpha \rightarrow 1$, we should obtain $U_{I I}^{I C}<U_{I I}^{\text {pooling }}$ for any level of $h$.

\section{N Proof of Proposition 13}

Given that $\delta>0$, the FOC with respect to $w_{I I, 1}$ and $w_{I I, 2}$ implies that $w_{I I, 1}<w_{I I, 2}$.

Concerning $\hat{h}^{I C}<\hat{h}^{F I}$, we use the definition of $e(h)$, in the IR'-IC' constraint. We deduce

$$
\begin{array}{r}
\int_{\underline{h}}^{\hat{h}}\left[u\left(w_{I I, 2}\right)-u(h+z)-\frac{G(h)}{g(h)} u^{\prime}(h+z)\right] d G(h) \geq 0 \\
\Leftrightarrow u\left(w_{I I, 2}\right) G(\hat{h})-\int_{\underline{h}}^{\hat{h}} u(h+z) d G(h)-\int_{\underline{h}}^{\hat{h}} \frac{G(h)}{g(h)} u^{\prime}(h+z) d G(h) \geq 0
\end{array}
$$

Using the fact that $d G(h)=g(h) d h$, we then have:

$$
u\left(w_{I I, 2}\right) G(\hat{h})-\int_{\underline{h}}^{\hat{h}} u(h+z) d G(h)-\int_{\underline{h}}^{\hat{h}} G(h) u^{\prime}(h+z) d h \geq 0
$$


The two last terms can be simplified using integration by parts and since $u(\underline{h}+z) G(\underline{h})=0$, we obtain:

$$
u\left(w_{I I, 2}\right) G(\hat{h})-u(\hat{h}+z) G(\hat{h}) \geq 0 \Leftrightarrow u\left(w_{I I, 2}\right)-u(\hat{h}+z) \geq 0
$$

implying that $w_{I I, 2} \geq \hat{h}+z$. Under full information, we have $\hat{h}^{F I}=y-z$, whereas in the asymmetric information, the threshold is $\hat{h}=w_{I I, 2}-z$. because $y>w_{I I, 2}$, we immediately deduce that $\hat{h}<\hat{h}^{F I}$.

Concerning $q_{I I}>q^{F I}$, we use the FOC with respect to $q$. It can be rewritten to the following one:

$$
\begin{aligned}
\frac{u\left(w_{I I, 1}\right)-u(z)}{u^{\prime}\left(w_{I I, 1}\right)}+\beta \frac{\left[G\left(\hat{h}^{I C}\right) u\left(w_{I I, 2}\right)+\int_{\hat{h}^{I C}}^{\bar{h}} u(h+z) d G(h)-\int_{\underline{h}}^{\bar{h}} U_{I}(h+z) d G(h)\right]}{u^{\prime}\left(w_{I I, 1}\right)} & \\
+y-w_{I I, 1}+\beta G\left(\hat{h}^{I C}\right)\left(y-w_{I I, 2}\right) & =\frac{1}{1-\epsilon_{H}\left(q_{I C}\right)} \frac{C}{H\left(q_{I C}\right)}
\end{aligned}
$$

because $\frac{\epsilon_{H}(q)}{1-\epsilon_{H}(q)} \frac{C}{H(q)}=\left(\frac{1}{1-\epsilon_{H}(q)}-1\right) \frac{C}{H(q)}$. In the full information case, we have $\delta=0$. The corresponding FOC could be rewritten in the following similar fashion:

$$
\begin{aligned}
\frac{u(y)-u(z)}{u^{\prime}(y)}+\beta \frac{\left[G\left(\hat{h}^{F I}\right) u(y)+\int_{\hat{h}^{F I}}^{\bar{h}} u(h+z) d G(h)-\int_{\underline{h}}^{\bar{h}} U_{I}(h+z) d G(h)\right]}{u^{\prime}(y)} & \\
+y-y+\beta G\left(\hat{h}^{F I}\right)(y-y) & =\frac{1}{1-\epsilon_{H}\left(q_{F I}\right)} \frac{C}{H\left(q_{F I}\right)}
\end{aligned}
$$

We observe three elements:

1. the "LHS" of the FOC for the IC economy is increasing in $w$;

2. when $w_{I I, 1}=w_{I I, 2}=y$, the "LHS" of the FOC for the IC economy coincides with the "LHS" of FOC for the FB economy;

3. the "RHS" of both equations are both of functional form and decreasing in $q$.

Thus to show $q^{F I}<q_{I I}$, it is sufficient to show that $L H S^{F I}>L H S^{I C}$. We will proceed in the following way:

(i) since $w_{I I, 1}<y$, we could obtain $\frac{u\left(w_{I I, 1}\right)-u(z)}{u^{\prime}\left(w_{I I, 1}\right)}+y-w_{I I, 1}<\frac{u(y)-u(z)}{u^{\prime}(y)}+y-y$, given that $\frac{u\left(w_{I I, 1}\right)-u(z)}{u^{\prime}\left(w_{I I, 1}\right)}+y-w_{I I, 1}$ is increasing in $w_{I I, 1}$.

(ii) The first inequality comes from the fact that $w_{I I, 1}<w_{I I, 2}$ and $u(w)$ is concave; the 
second inequality is due to the same reason stated in $(i)$ :

$$
\begin{aligned}
& \frac{G\left(\hat{h}^{I C}\right) u\left(w_{I I, 2}\right)+\int_{\hat{h}^{I C}}^{\bar{h}} u(h+z) d G(h)-\int_{\underline{h}}^{\bar{h}} U_{I}(h+z) d G(h)}{u^{\prime}\left(w_{I I, 1}\right)}+G\left(\hat{h}^{I C}\right)\left(y-w_{I I, 2}\right) \\
< & \frac{G\left(\hat{h}^{I C}\right) u\left(w_{I I, 2}\right)+\int_{\hat{h}^{I C}}^{\bar{h}} u(h+z) d G(h)-\int_{\underline{h}}^{\bar{h}} U_{I}(h+z) d G(h)}{u^{\prime}\left(w_{I I, 2}\right)}+G\left(\hat{h}^{I C}\right)\left(y-w_{I I, 2}\right) \\
< & \frac{G\left(\hat{h}^{F I}\right) u(y)+\int_{\hat{h}^{F I}}^{\bar{h}} u(h+z) d G(h)-\int_{\underline{h}}^{\bar{h}} U_{I}(h+z) d G(h)}{u^{\prime}(y)}+G\left(\hat{h}^{F I}\right)(y-y)
\end{aligned}
$$

Thus the $L H S^{F B}>L H S^{S B}$, which implies $R H S^{F I}>R H S^{I C}$, and it turns out that $q^{F I}<q_{I I}$ by the fact that the right hand sides are of the same functional form and decreasing in $q$.

To conclude, it implies that $F\left(q_{I I}\right) G\left(\hat{h}^{I C}\right)<F\left(q^{F I}\right) G\left(\hat{h}^{F I}\right)$, the job matching is inferior in the IC economy. 